\title{
Analysis of Cumulative Damage Characteristics of Long Spiral Belled Pile under Horizontal Cyclic Loading at Sea
}

\author{
Haian Liang $\mathbb{D}^{1},{ }^{1}$ Hao Zeng $\mathbb{D}^{1},{ }^{1}$ Kaiwei Cao, ${ }^{2}$ Chao Liu, ${ }^{1}$ and Xinjun Cheng ${ }^{1}$ \\ ${ }^{1}$ School of Civil and Architectural Engineering, East China University of Technology, Nanchang 330013, China \\ ${ }^{2}$ Jiangxi Zhongheng Underground Space Technology Co., Ltd.,, Nanchang 330052, China \\ Correspondence should be addressed to Haian Liang; lianghaian@foxmail.com
}

Received 16 June 2021; Revised 5 September 2021; Accepted 21 October 2021; Published 9 November 2021

Academic Editor: Erkan Oterkus

Copyright (c) 2021 Haian Liang et al. This is an open access article distributed under the Creative Commons Attribution License, which permits unrestricted use, distribution, and reproduction in any medium, provided the original work is properly cited.

In order to study the cumulative damage and failure characteristics of long spiral belled pile under horizontal cyclic loading of offshore wind and waves, a series of indoor experiments on single piles under horizontal cyclic load were carried out. The cycle times as well as load amplitude at the same frequency were considered during the horizontal pseudo-static cyclic tests. On the basis of the distribution of pile deflection, bending moment, and Earth pressure around the pile, the pile-soil interaction was comprehensively discussed. The cumulative energy dissipation characteristics were introduced to describe the damage of test piles. Meanwhile, the effects of load amplitude and cycle times on the cumulative damage of long spiral belled piles were discussed. A power function model for energy dissipation coefficient prediction under multi-stage cyclic load was proposed. The results show that the horizontal peak bearing capacity of long spiral belled pile is increased by $57.2 \%$ and $40.4 \%$, respectively, as compared with the straight pile and belled pile under the same conditions. The horizontal displacement mainly occurs at the upper part of the pile. Under the condition of limited cyclic times, the load amplitude has more significant effect on the bearing characteristics of the long spiral belled pile. In contrast to the straight pile and belled pile, the long spiral belled pile has better energy dissipation capacity, and the rank of the energy dissipation capacity of these three piles is long spiral belled pile $>$ belled pile $>$ straight pile. The power function model can well reflect the cumulative damage characteristics of long spiral belled pile under horizontal cyclic loading, and there is a good linear relationship between power function model parameters and load amplitude. The energy dissipation coefficient of long spiral belled pile with diverse cycle times at different mechanical stages of test pile is analysed. Then, the recommended power function model parameters according to different failure stages are proposed. The verification example indicates that the prediction results are close to the measured values with a calculation error of $22 \%$. The prediction model can provide a certain reference for the application of long spiral belled pile in marine structures.

\section{Introduction}

Pile foundations in the field of marine engineering are often subjected to horizontal cyclic loading caused by factors such as sea wind and waves. Local permanent cumulative damage at one or several places may appear at a pile under the horizontal cyclic loading, and crack or sudden fracture damage can occur after a certain number of cycles. The phenomena mentioned above can seriously affect the normal use of pile foundation and safety of the superstructure.

The bearing characteristics and deformation law of pile foundation under the horizontal cyclic load of sea waves are interesting topics for domestic and foreign scholars. Rao [1],
Basack [2], Achmus [3], Liao [4], and Kong [5] studied the effects of cyclic load amplitude, cycle times, single pile size, and buried depth on the stress characteristics and deformation of single pile, and concluded that load amplitude, cycle times, and single pile size effect have great influence on the stress characteristics and deformation of single pile. Niemann $[6,7]$ has carried out centrifuge model tests and $1 \mathrm{~g}$ model tests of single pile and group piles under lateral cyclic load in sand, and discussed the influence of pile group geometry, pile spacing, and cyclic load amplitude on the cumulative displacement of group piles. Cyclic load has a significant impact on the initial stiffness of $\mathrm{p}-\mathrm{y}$ curve, and the initial stiffness decreases with the increase of cyclic times. 
Basack [8-10] developed a new lateral cyclic load application device for model pile foundation. Through comprehensive experimental research and finite element analysis, the bending moment distribution and bearing characteristic response of pile groups under horizontal cyclic load in soft soil area were studied, and the influence law of horizontal load parameters, namely, cycle times, frequency, and amplitude on degradation factors, was analysed. A series of summary and analysis were made on the lateral cyclic load of pile foundation in marine environment. According to previous research results, some design suggestions were put forward for pile foundation under cyclic load. Chen [11] carried out an experimental study on the pipe pile in soft soil area under static pressure and cyclic combined load, and explored the influence of static load, cyclic load, and load level. Three modes of cyclic characteristics of pile top displacement are given: rapid stability, gradual development, and severe failure. According to the cycle stability diagram, the cycle stability criterion is divided into stable region, metastable region, and unstable region, and the corresponding limit values are obtained according to the test results. Liu [12] studied the deformation characteristics of composite foundation supported by geogrid piles under cyclic loading through a series of model tests, and analysed the effects of load, geogrid layers, pile types, and other factors on the performance of composite foundation. The relationship between foundation settlement and cycle times is analysed by the numerical fitting method.

Lin [13] applied the concept of strain superposition to evaluate the strain accumulation of laterally loaded piles in sandy soil, and found that soil properties, pile embedding mode, cyclic loading mode, and other factors can significantly affect the performance of horizontally loaded piles. Rosquoet et al. [14] conducted centrifuge tests on sandy soil, and found that the maximum displacement was generated in the first cycle, and the cumulative deformation was mainly generated in the short-term cycle. Zhang et al. [15]conducted a single pile model test in sandy soil foundation and also reached a similar conclusion. The cumulative displacement of pile top was mainly concentrated in the shortterm cycle, and the short-term effect of the cycle was greater than the long-term effect. LeBlanc et al. [16] carried out unidirectional and bidirectional cyclic loading tests in dry sand with different dry densities. They believed that the cumulative stress and deformation of pile foundation under horizontal cyclic loading was related to the unloading stiffness, and the expression formula was given. Arshad [17] and Richards et al. [18] compared the model test of one-way and two-way cyclic loading and found that under the same load amplitude, the cumulative deformation caused by twoway cyclic loading was greater than that caused by one-way cyclic loading. Bolton [19], Alizadeh, Davisson [20], Little [21], Long [22], and Verdure [23] established a logarithmic function or power function model between the development trend of pile foundation's cumulative deformation and the number of cycles under horizontal cyclic load through model tests and field tests. Luo et al. [24], based on numerical simulation, used the power function model to predict the cumulative deformation of pile foundation under different loads. Peralta et al. [25] carried out horizontal cyclic loading tests of rigid pile and flexible pile in sandy soil, discussed the influence law of cyclic number and load amplitude on accumulated damage and deformation of pile foundation, and presented the relationship between cumulative damage and deformation of rigid pile under long-term horizontal cyclic load and times of cyclic loading.

Many researchers have found that the cumulative deformation of single pile under horizontal cyclic loading mainly occurs in short-term cycle, and in the early stage of cyclic loading, the number of cycles and loading mode can obviously affect its bearing characteristics. The long spiral belled pile is made by improving the manufacturing technology and construction equipment of the spiral pile, setting an enlarged head at the pile end on the basis of the spiral pile. A new type of pile is formed, which increases the compaction between pile and soil beside pile due to the existence of enlarged head at pile end and thread of pile body, thus greatly improving the bearing capacity of pile. At present, the long spiral belled pile is widely used in engineering, but its application and research in marine structures are few. Therefore, it is of great significance to study the bearing and damage characteristics of long spiral belled piles under the approximate horizontal cyclic loads such as offshore wind and waves.

This study focuses on the pile-soil interaction and energy dissipation characteristics of offshore long spiral belled piles subjected to the horizontal cyclic loading. Three types of piles, namely, long spiral belled pile, straight pile with equal cross section, and belled pile, are selected. A set of single pile model tests under horizontal cyclic load were carried out with an indoor model box. As limited to the test conditions, the loading frequency is $0.01 \mathrm{~Hz}$. Cyclic reciprocating loads with different load amplitudes are applied at the same frequency in the test. Through the distribution of pile deflection, bending moment, and Earth pressure around the pile, the influence of cyclic load amplitude and cycle times on the interaction between the long spiral belled pile and the soil around the pile is discussed. By analysing its hysteretic characteristics and skeleton curve, the cumulative energy dissipation characteristics are used to reflect the damage of test pile, and the influence of load amplitude and cycle times on the cumulative damage of long spiral belled pile is discussed. The power function prediction model of energy dissipation coefficient under multi-stage cyclic loading is put forward. It provides a reference for the application of long spiral belled pile in offshore engineering.

\section{Experiment}

2.1. Manufacture of Model Pile. The test model pile is a precast concrete pile, and the similarity ratio is calculated by taking the long spiral belled pile with pile length $L=12 \mathrm{~m}$, pile diameter $D=0.6 \mathrm{~m}$, and concrete strength C35 as the prototype. It is determined that the proportional constant $S_{\mathrm{L}}$ is 10 , the elastic modulus similarity ratio $C_{\mathrm{E}}=1 / 5$, and the straight pile and belled pile are set as the control group. The geometric dimensions of the three indoor model piles designed based on the similarity ratio are shown in Table 1. 
TABle 1: Parameter table of model pile.

\begin{tabular}{|c|c|c|c|c|c|}
\hline Pile type & Length (m) & Diameter $(\mathrm{mm})$ & Enlarged head diameter $(\mathrm{mm})$ & Reinforcement & $\begin{array}{l}\text { Reinforcement cage } \\
\text { length }(\mathrm{m})\end{array}$ \\
\hline Long spiral belled pile (LK) & 1.2 & 60 & 90 & $8 \Phi 2$ & 1.0 \\
\hline Belled pile (KZ) & 1.2 & 60 & 90 & $8 Ф 2$ & 1.0 \\
\hline Equal cross section straight pile (ZZ) & 1.2 & 60 & - & $8 Ф 2$ & 1.0 \\
\hline
\end{tabular}

According to the similarity theory, the concrete strength of the test pile is calculated, and the mixing ratio of micro-particle concrete is determined as cement: sand: gravel: water $=1: 2.5: 3.5: 1$. The model pile is cured under standard conditions for 28 days according to the specification requirements. After indoor uniaxial unconfined compressive strength test, the compressive strength of micro-particle concrete is $7.5 \mathrm{MPa}$, and the elastic modulus is $6.4 \mathrm{GPa}$.

2.2. Control of Bearing Stratum of Foundation Soil. The medium coarse sand is used as foundation soil. According to the indoor geotechnical test, the physical and mechanical parameters of foundation soil are measured as shown in Table 2. The uneven coefficient is $C_{\mathrm{u}}=5$, the curvature coefficient is $C_{\mathrm{c}}=1.65$, and the sand used is well graded. During the filling process, the soil at different depths was sampled at fixed points, and the average dry density and wet density in the model box were $1.57 \mathrm{t} / \mathrm{m}^{3}$ and $1.68 \mathrm{t} / \mathrm{m}^{3}$, respectively.

The design thickness below the pile end is $0.8 \mathrm{~m}$, and the buried depth of the test pile is $1.2 \mathrm{~m}$. The model box is filled by the layered tamping method, and it is leveled and tamped every $20 \mathrm{~cm}$. When filling the next layer, the surface is shaved to avoid artificial stratification. In order to accurately and uniformly control the bearing capacity and compactness of the foundation, after each layer is tamped, the fixed-point measurement is carried out by the foundation bearing capacity meter. The bearing capacity of foundation soil is controlled at $165 \mathrm{kPa}$, so as to ensure that the bearing capacity of each test foundation is the same. When the test pile is buried, the laser level is used for calibration to ensure that the pile body is buried vertically, and the sand in the model box is fully compacted under the action of gravity after standing for $24 \mathrm{~h}$.

\subsection{Instruments and Devices}

2.3.1. Horizontal Loading Device. The indoor pseudo-static push-over test adopts YT-XT-3000 underground space pseudo-static geotechnical model test box independently developed by East China University of Technology. The internal dimensions of the model box are $3 \mathrm{~m}$ (length): $2 \mathrm{~m}$ (width): $2 \mathrm{~m}$ (height), and both sides are made of tempered glass, which is convenient for observing the changes of test components and the surrounding soil during the test. The test loading device is a servo horizontal actuator controlled by a horizontal electric cylinder, It is connected with the actuator through the pile head clamp, and the model box and loading device are shown in Figure 1.
TABLE 2: Mechanical parameters of sand and soil.

\begin{tabular}{lccccccc}
\hline$\rho\left(\mathrm{g} / \mathrm{cm}^{3}\right)$ & $\rho_{\mathrm{d}}$ & $\omega(\%)$ & $C_{\mathrm{u}}$ & $C_{\mathrm{c}}$ & $\Phi\left(^{\circ}\right)$ & $c(\mathrm{kPa})$ & $\mathrm{E}(\mathrm{MPa})$ \\
\hline 2.67 & 0.6 & 4.27 & 5 & 1.65 & 22 & 4.64 & 20 \\
\hline
\end{tabular}

2.3.2. Pile Strain Measuring Element. Twelve BX120-3AA strain gauges were symmetrically arranged on the tension side and the compression side of the pile, with the spacing of $3 \mathrm{D}(18 \mathrm{~cm})$, as shown in Figure 2. DH3816 N dynamic signal testing system was used to collect the strain data. The resistance value of the strain gages was $119.9 \pm 0.1 \Omega$, and the sensitivity was $2.08 \pm 1 \%$.

2.3.3. Measuring Equipment for Horizontal Displacement of Pile Top. In order to reduce the displacement error caused by the gap in the connecting part when the actuator carries out reciprocating cyclic loading, two YHD-100 displacement sensors are respectively erected on both sides of the pile head. And when installing, use a level ruler to ensure that it is placed horizontally.

2.3.4. Distribution of Earth Pressure Box around Pile. HZC-MC piezoresistive Earth pressure sensor is used to measure the change of Earth pressure around the long spiral belled pile under horizontal cyclic load. In the horizontal direction, the tension side and compression side are buried two times the pile diameter $(12 \mathrm{~cm})$ away from the pile body, and the compression side is arranged along the horizontal direction at a distance of $2 \mathrm{~d}, 4 \mathrm{~d}, 6 \mathrm{~d}, 8 \mathrm{~d}$, and $10 \mathrm{~d}$ from the pile. In the vertical direction, it is arranged at a distance of $0.18 \mathrm{~m}$. The arrangement of Earth pressure sensors is shown in Figure 3, and Figure 4 is the physical drawing of Earth pressure box embedment.

2.3.5. Measuring Equipment for Pile Horizontal Displacement. SAAF200 array displacement meter is used to measure the horizontal deflection of the model pile in the model box. The array displacement meter is small in diameter, soft and rigid. By fixing the array displacement meter on the side of the pile through insulating tape and binding tape, the influence of the array displacement meter on the strength and displacement of the pile can be ignored, and the real-time change of the pile shape during loading can be accurately monitored. The array displacement meter has a total length of $1800 \mathrm{~mm}$ and a total of 12 measuring points. A total of 9 effective measuring points were arranged from the bottom of the pile to the end of the pile for monitoring. 


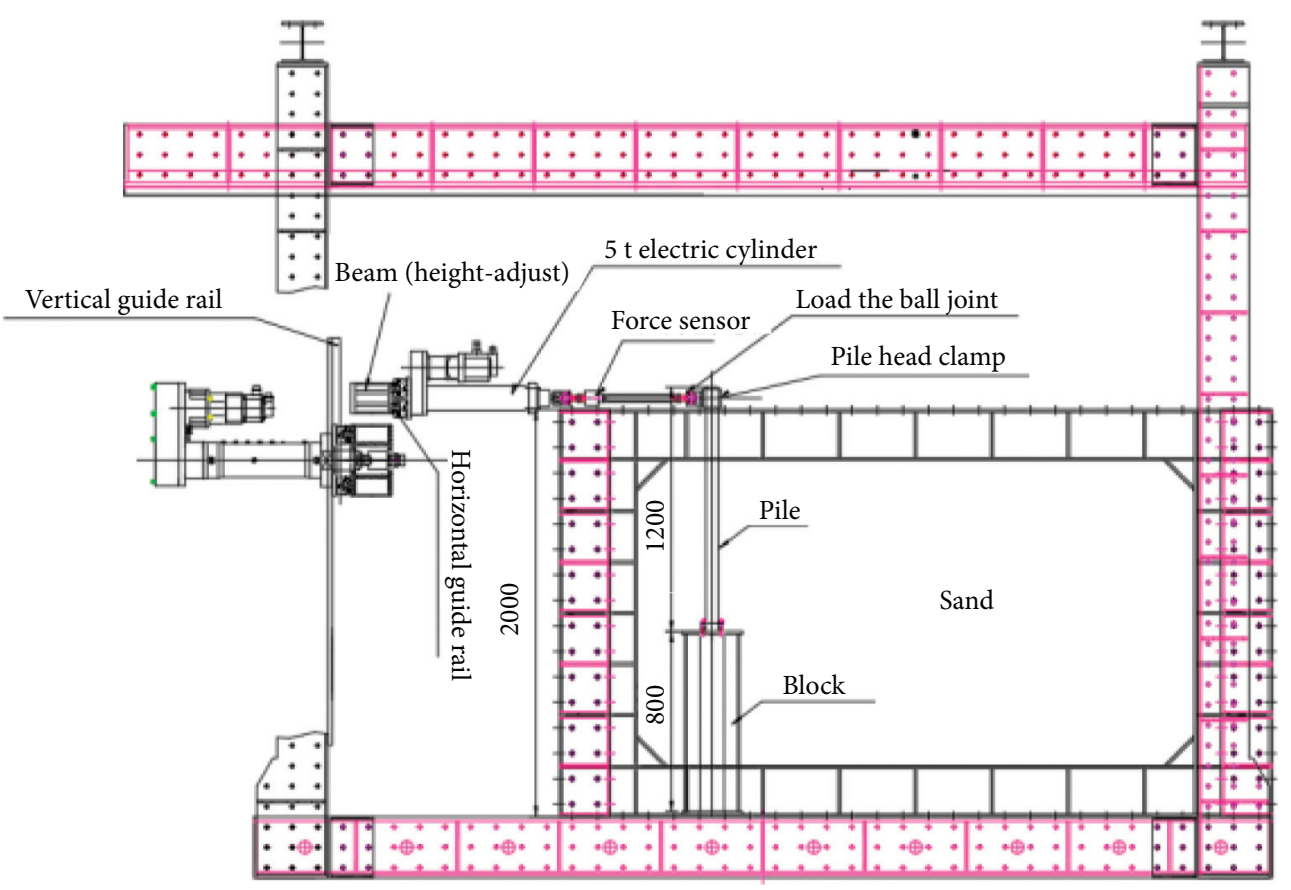

FIgURE 1: Horizontal loading device.

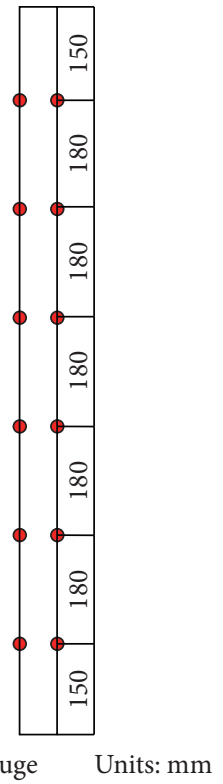

FIGURE 2: Strain gauge distribution of pile body.

2.4. Test Loading Scheme. Before the indoor test, the unidirectional static load test is used to carry out the model pre-test, and the ultimate bearing capacity of the straight pile is determined to be about $0.9 \mathrm{kN}$. In order to better simulate the sea wind and wave load, through the mutual comparison and analysis between the theoretical calculation results and the pretest ultimate load, according to the "Code for Port Engineering Pile Foundations" [26] and "Code for Building Seismic Test" [27], the loading scheme is formulated as follows:

(1) The multi-stage horizontal cyclic reciprocating loading method. Each stage has a cycle number of 6

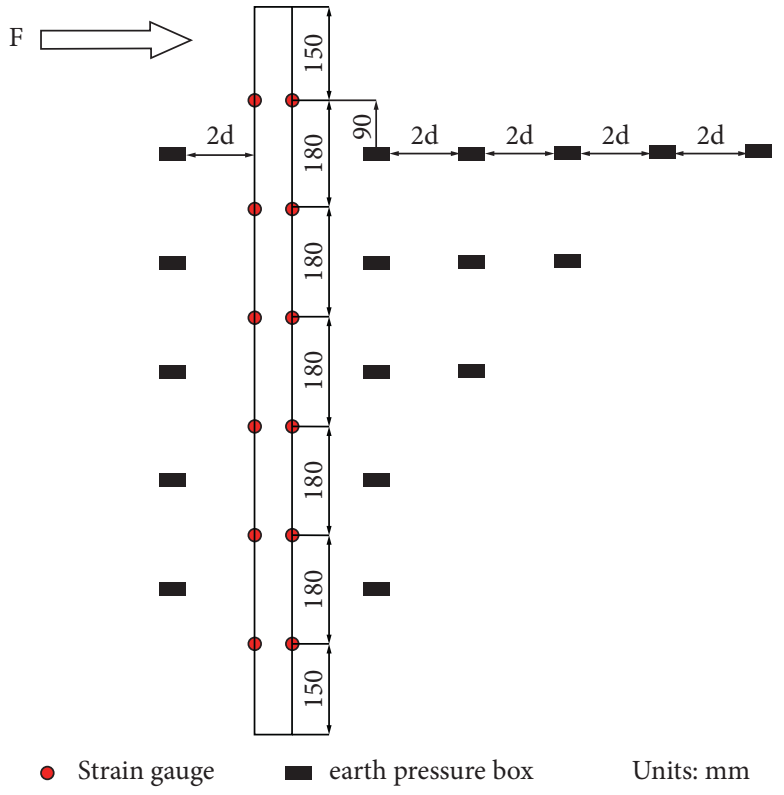

FIGURE 3: Embedded distribution diagram of Earth pressure box.

times. $2 / 3(0.53 \mathrm{kN})$ of the straight pile ultimate bearing capacity is taken as the initial loading value, and the multi-stage cyclic loading is carried out in increments of $0.1 \mathrm{kN}$. The loading history curve is shown in Figure 5(a).

(2) In order to further study the influence of cyclic loading times on long spiral belled pile, the singlestage cyclic loading method was adopted to load the test pile until it failed, and $0.53 \mathrm{kN}$ was taken as the initial loading value of fatigue loading. The loading diagram is shown in Figure 5(b). 


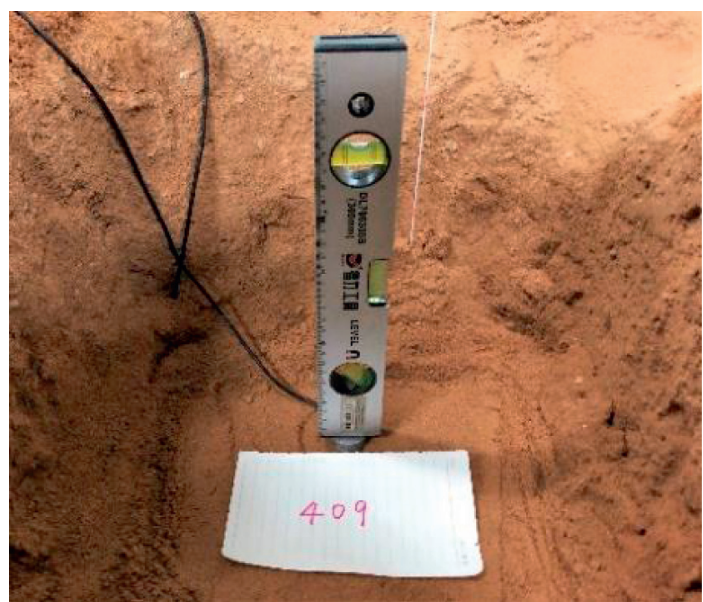

(a)

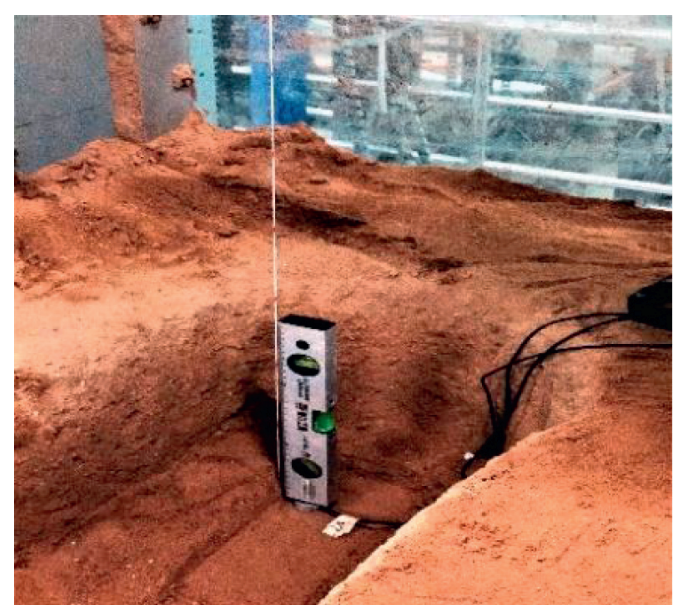

(b)

FIgURE 4: Burial diagram of Earth pressure box.

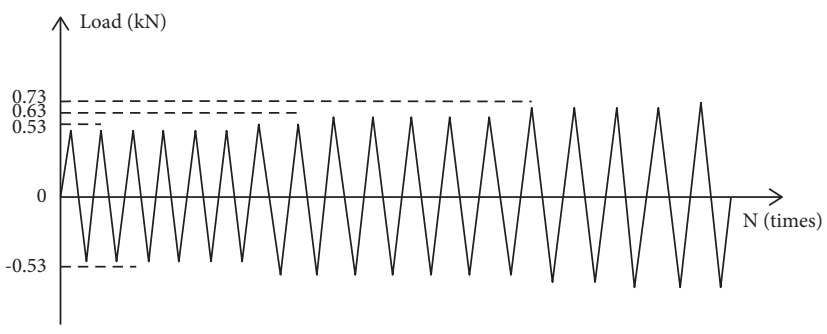

(a)

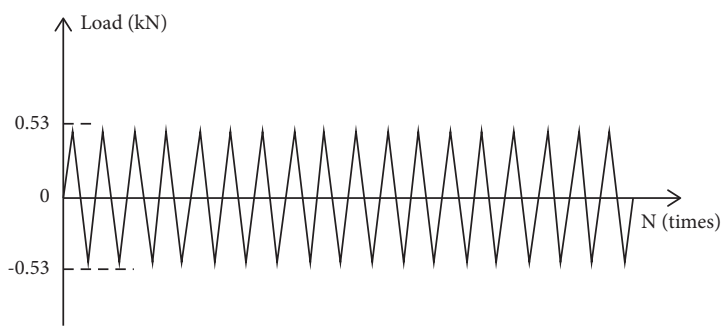

(b)

Figure 5: Time history curves of two loading modes. (a) Multi-stage cyclic loading. (b) Single-stage cyclic loading.

(3) The termination conditions of indoor cyclic loading are as follows:

(a) The pile body is obviously damaged and fractured;

(b) The monitored horizontal displacement of pile top has exceeded $30 \mathrm{~mm}$;

(c) The load applied by the actuator is reduced to $85 \%$ of the maximum load;

In this indoor model test, 4 long spiral belled piles, 1 belled pile, 2 straight piles, and a total of 7 model piles were selected and divided into two groups for the test. The number and loading method of each test pile are shown in Table 3.

\section{Results and Discussion}

3.1. Failure Form. The failure modes of the seven test piles were observed. During the process of horizontal cyclic loading, the bending failure of the testing pile occurred. The failure modes are shown in Figure 6.

At the initial stage of horizontal cyclic loading, the pile with equal cross section and the soil around the pile are in the elastic stage. The soil around the pile gradually changes from elastic deformation to plastic with the load increasing, and the soil around the pile gradually degrades, resulting in bending deformation. A main crack with a large width appears in the mid-span L/4 $(30 \mathrm{~cm})$ away from the top of the pile, when the load is continuously putting on the test pile. Along with the load growth, the pile produces 2-3 micro-cracks along the upper and lower directions of the main crack. Finally, the pile body will produce obvious cracks since large displacement deformation occurs. Figure 6(a) shows the failure form.

The failure mode of the belled pile is similar to that of the straight pile, with cracks appearing at $0.38 \mathrm{~m}$ away from the pile tip. However, due to the existence of the enlarged head, when the enlarged bottom pile reaches the ultimate load, stress concentration occurs near the enlarged head, causing damage. The prestressed reinforcement on the compression side is seriously deformed and the concrete is crushed, and the bearing capacity of the test pile decreases rapidly. The failure mode is shown in Figure 6(b).

Under multi-stage cyclic loading, when the straight pile, the belled pile, and the long spiral belled pile are loaded until failed, a main crack perpendicular to the pile body appears at about $0.3 \mathrm{~m}$ near the top of the pile. At the same time, the steel bars yield and the concrete of the pile body undergoes obvious fracture failure. Comparing it with the belled pile, its bearing capacity has been correspondingly increased, and the cracks of the pile are fully developed. The joint between the belled head and the pile body may fracture due to stress concentration. The failure mode is shown in Figure 6(c). There is no obvious damage in the LK4, when it is subjected to the single-stage cyclic 
TABLE 3: Pile loading group for indoor test.

\begin{tabular}{lccc}
\hline Loading method & Straight pile & Expanding bottom pile & Long spiral belled pile \\
\hline Multi-stage cyclic loading & ZZ1, ZZ2 & KZ1 & LK1, LK2, LK3 \\
Single-stage cyclic loading & - & - & LK4 \\
\hline
\end{tabular}

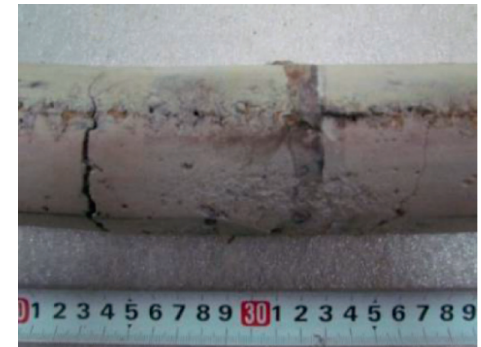

(a)

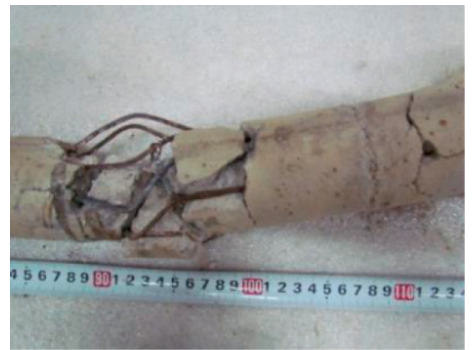

(b)

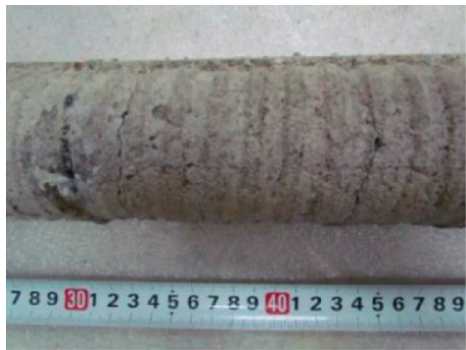

(c)

Figure 6: Failure mode of test pile. (a) Straight pile. (b) Expanding bottom pile. (c) Long spiral belled pile.

load with $0.53 \mathrm{kN}$, because the load value and number of cycles is not big enough to the pile.

A summary of the failure forms of each pile type is shown in Table 4 . By doing contrastive analysis of the failure conditions of the three pile types in the loading process, the failure process of the test pile under multilevel horizontal cyclic load can be divided into the following stages:

(1) Initial cracks appear in the upper part of the pile body at the initial stage of loading;

(2) New cracks will be generated around the initial cracks due to the increase of load, and the initial cracks will continue to develop and increase in width;

(3) After the specimen yields, the initial crack width develops further, resulting in extremely obvious main cracks;

(4) The brittle failure of pile body produces obvious main cracks, which leads to the inability to bear more loads.

When the test pile is damaged, the maximum bending moment of the pile body almost coincides with the position where the horizontal deflection of the test pile is close to $0 \mathrm{~mm}$, and bending moment deformation occurs at this position, which leads to fracture and failure to form the main crack, and the deflection of the pile body is basically $0 \mathrm{~mm}$ below the depth of the main crack. The failure modes of the three pile types are basically the same, but the number of cracks and the range of expansion are different. The width of the main crack of long spiral belled pile is significantly smaller than that of the bottomexpanding pile and straight pile, and under the condition of larger load, there is no obvious crushing of concrete or breaking of steel bars. It is indicated that the existence of screw thread and expansion head of long spiral belled pile can affect the failure mode of test pile to a certain extent and improve the bearing capacity.
3.2. Influence of Pile-Soil Interaction of Long Spiral Belled Pile under Horizontal Cyclic Loading. In offshore structures, pile foundations are often subjected to cyclic loads caused by sea waves, ship impacts, or moving vehicles. Under the longterm cyclic loads, pile bodies are damaged cumulatively, which leads to changes in the overall stability of pile foundations. Under this cyclic action, the interaction between pile and soil around the pile is destroyed, and the strength and stiffness of the soil around the pile are gradually degraded, which leads to the gradual degradation of the bearing capacity of the pile and the large displacement of the pile, seriously affecting the normal use of pile foundation and the safety of the superstructure. The weakening of lateral bearing capacity of pile foundation and the degradation of soil around the pile are mainly affected by cyclic loading parameters.

In order to better study the single pile response of long spiral belled pile under horizontal cyclic loading, the multistage cyclic loading of long spiral belled pile was carried out by indoor model test. As limited to the test conditions, the loading frequency is $0.01 \mathrm{~Hz}$. The influences of different load amplitudes and cyclic times on pile-soil interaction of long spiral belled pile were mainly discussed. The pile-soil interaction of long spiral belled pile is analysed and discussed by using the changes of deflection, bending moment, and Earth pressure around the pile.

\subsubsection{Influence of Load Amplitude on Pile-Soil Interaction.}

Based on the display displacement meter and the push rod displacement meter readings, the pile body deflection distribution trend of LK2 in the process of forward and reverse loading was plotted, as shown in Figure 7.

Under the condition of different load amplitudes, the deflection of the pile body decreases gradually along the depth, and the deformation of the test pile presents a parabolic change as a whole. The peak displacement is always at the top of the pile, and the position does not move with the increase of load; with the increase of load amplitude, under 
TABLE 4: Failure statistics of three pile types.

\begin{tabular}{|c|c|c|c|}
\hline Number & Destruction description & $\begin{array}{l}\text { Maximum } \\
\text { bending } \\
\text { moment } \\
\text { position }\end{array}$ & $\begin{array}{l}\text { Maximum } \\
\text { bending } \\
\text { moment }(\mathrm{kN} \cdot \mathrm{m})\end{array}$ \\
\hline ZZ1 & Fracture at $0.24 \mathrm{~m}$, obvious crack at $0.36 \mathrm{~m}$, and slight crack at $0.43 \mathrm{~m}$. & $0.4 \mathrm{~m}$ & 0.38 \\
\hline ZZ2 & Multiple cracks appeared at the position of $0.1 \mathrm{~m}-0.4 \mathrm{~m}$ pile body. & $0.6 \mathrm{~m}$ & 0.33 \\
\hline KZ1 & $\begin{array}{l}\text { At } 0.9 \mathrm{~m} \text {, the concrete was obviously broken, the steel bar yielded, and a large crack } \\
\text { appeared at the connection position of the enlarged head, and the crack appeared } \\
\text { at the location at a depth of } 0.38 \mathrm{~m} \text {. }\end{array}$ & $0.6 \mathrm{~m}$ & 0.58 \\
\hline LK1 & $\begin{array}{c}\text { An obvious crack appeared at } 0.45 \mathrm{~m} \text {, and no damage occurred at other positions of } \\
\text { the pile body. }\end{array}$ & $0.6 \mathrm{~m}$ & 0.48 \\
\hline LK2 & $\begin{array}{l}\text { Two cracks appeared at } 0.32 \mathrm{~m} \text { and } 0.45 \mathrm{~m} \text {, and the connection between the } \\
\text { expanding head and the pile body was fractured. }\end{array}$ & $0.6 \mathrm{~m}$ & 0.48 \\
\hline LK3 & $\begin{array}{l}\text { At } 0.25 \mathrm{~m} \text {, the concrete fracture occurred obviously, the steel bar yield, and the pile body } \\
\text { appeared an obvious crack at } 0.6 \mathrm{~m} \text {. }\end{array}$ & $0.6 \mathrm{~m}$ & 0.43 \\
\hline LK4 & There is no obvious damage to the pile body. & - & - \\
\hline
\end{tabular}

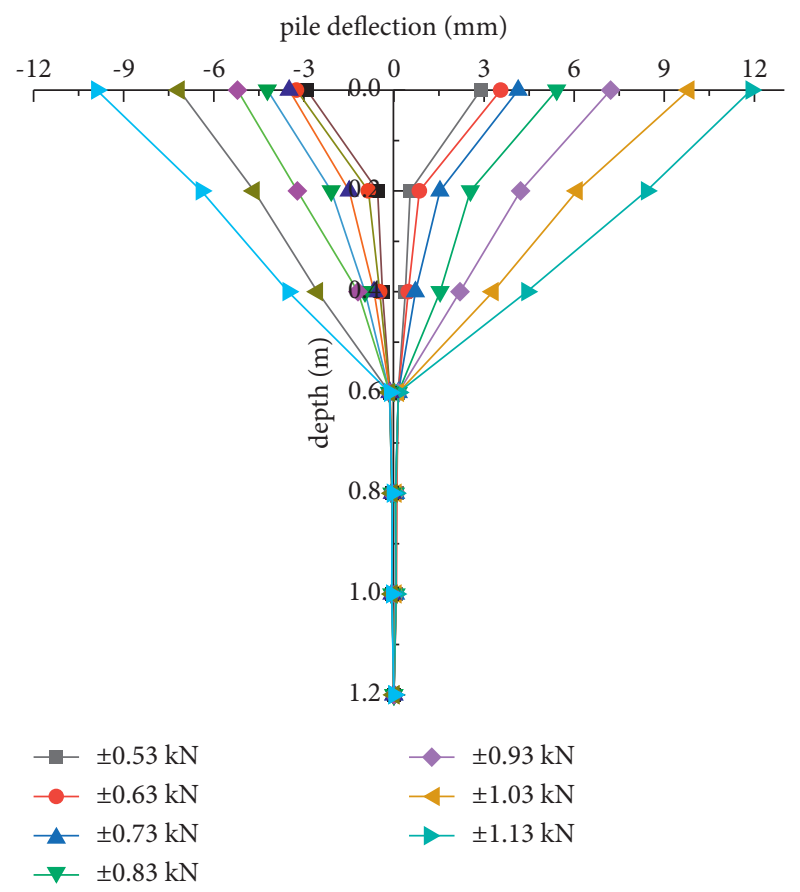

Figure 7: Variation of pile deflection with depth during LK2 positive and negative loading.

the same load increment, the displacement of long spiral belled pile will change more obviously when the load amplitude is larger. During the loading process, the horizontal displacement of the pile body mainly occurs in the upper part of the pile. It can be seen that the amplitude of cyclic load has a great influence on the displacement of the long spiral belled pile under the action of sea wind and waves, and the displacement of the pile body gradually increases with the increase of load amplitude.

The bending moment of LK2 pile under cyclic loading is calculated, as shown in Figure 8.

It can be seen from Figure 8 that the bending moment of pile body presents a curve change of first increasing and then decreasing with the increase of depth. When the load amplitude is small, the bending moment of test pile increases slowly. Combined with the failure mode and deflection analysis of the test pile, it can be found that the maximum bending moment of pile coincides with the zero point of pile horizontal displacement. The maximum bending moment of the whole pile body is about $0.6 \mathrm{~m}$ in depth (about 9 times the pile diameter from the ground), and fracture failure occurs at this position to form the main crack. Due to the existence of the enlarged head at the pile end, the contact area between the pile and the soil around the pile increases, which leads to the change of the soil resistance at the pile end, and the bending moment gradually increases in the depth range of $1.0-1.2 \mathrm{~m}$.

In the process of forward and reverse loading, bending moments are symmetrically distributed under different load amplitudes. The maximum bending moments of LK2 under positive and negative loading are $0.48 \mathrm{kN} \cdot \mathrm{m}$ and $-0.45 \mathrm{kN} \cdot \mathrm{m}$, respectively. The difference in the maximum bending moment value during forward and reverse loading may be due to the fact that the shallow soil is gradually compacted, the resistance provided by the soil is gradually increased, and the soil is gradually transformed from elastic deformation to plastic deformation, which leads to a slight difference in bending moment distribution between the front and back sides due to the plastic deformation of the original active Earth pressure side due to soil compaction during reverse loading. In the process of forward loading, the test pile shows the characteristics of a rigid pile, with a bending point at $0.8 \mathrm{~m}$, and the bending moment below this depth is negative. In the process of reverse loading, the bending moment of pile body is distributed on the same side of the horizontal load point, and increases first and then decreases with the increase of buried depth.

Due to the existence of pile threads, the thread blades around the pile extended from the pile body change the interaction between pile and soil around the pile, and the interaction between the middle section of pile thread spacing and soil around the pile also changes, which makes the pile and soil around the pile produce a better bonding effect and increases the positive pressure of soil around the pile on the pile side, thereby improving the bearing performance of the long spiral belled pile. 


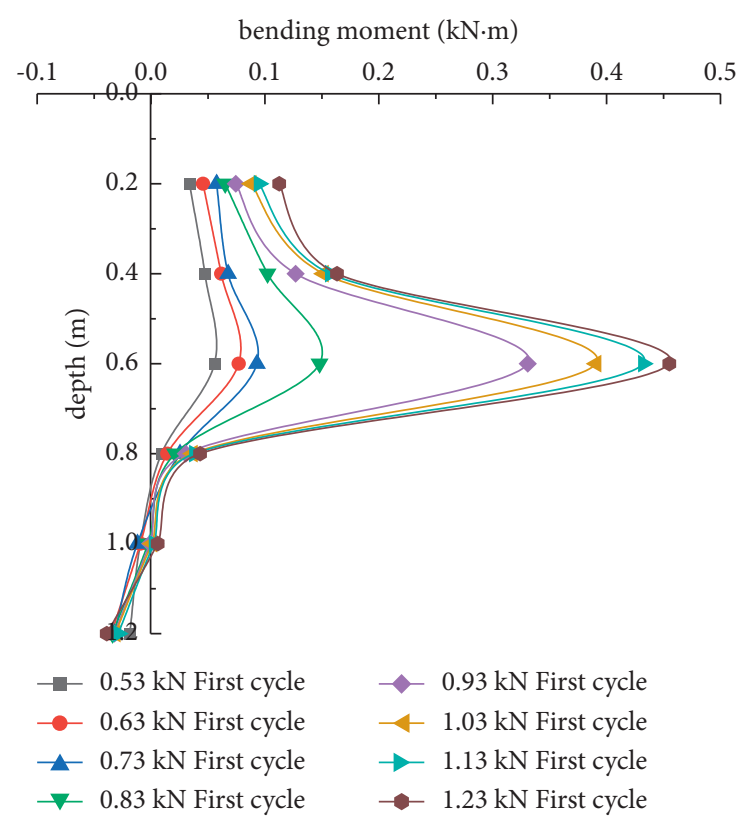

(a)

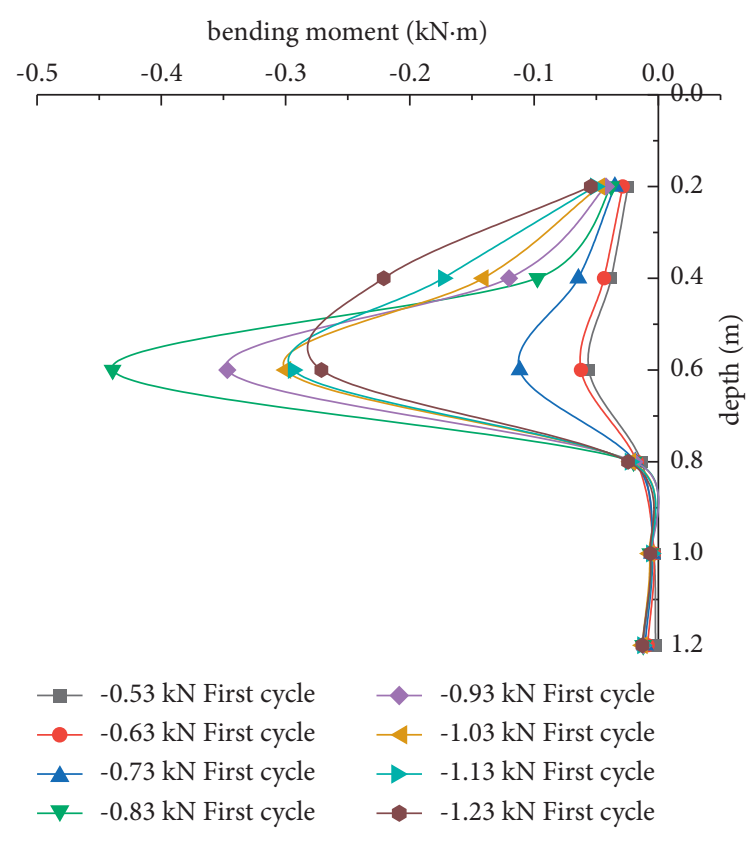

(b)

FIGURE 8: Bending moment distribution diagram of pile body in LK2. (a) In forward loading process. (b) In reverse loading process.

In the process of test loading, the change of increment of Earth pressure around the pile is shown in Figure 9.

In the process of forward loading, the increment of Earth pressure increases with the increase of load amplitude. The maximum Earth pressure is located at $0.3 \mathrm{~m}$ depth, and gradually decreases with the increase of pile embedment depth. In the range of $0.2 \mathrm{~m}-0.5 \mathrm{~m}$ depth, the horizontal bearing capacity of long spiral belled pile is mainly controlled by soil above $0.5 \mathrm{~m}$ depth. When the load amplitude is small, the soil on the compression side is compacted, which leads to a slight increase in the Earth pressure. During the loading process, the reverse bending point occurs at the variable cross section $(0.9 \mathrm{~m})$ due to stress concentration, and the enlarged head section shows a reverse movement trend, which makes the Earth pressure increase at the upper part of the enlarged head.

In the process of reverse loading, the original side behind the pile becomes the compression side of the pile. Part of the original compacted soil is restored by elastic deformation, and part of the soil that has produced plastic deformation is still compacted, so the soil pressure under forward and reverse loading does not show a symmetrical distribution trend.

The disturbance range of soil around the pile is $2-4$ times of the pile diameter, and the soil pressure around the pile is significant with the change of the depth. With the increase of the depth, the soil pressure on the pile side decreases gradually. When the depth is less than 9 times the pile diameter, the soil pressure on the pile side decreases to about $0.3 \mathrm{kpa}$. In the horizontal direction, the maximum influence range of soil is near the top of the pile body. With the increase of the pile depth, the influence range gradually decreases and presents an approximate conical shape.
With the increase of load amplitude, the pile begins to incline, the soil around the pile is squeezed by the pile body, resulting in deformation, and the soil on the compression side is continuously compacted, and two micro cracks spread outward along the center of the pile gradually appear. At this time, the cracks mainly develop along the diameter of the pile, the soil is further compacted and uplifted, and the initial cracks further develop and expand. When the load amplitude is large, the soil compaction area changes from elastic to irreversible plastic deformation, and the pile body is gradually damaged. At this time, the soil cracks around the pile are connected, the soil is completely destroyed, and obvious voids are generated at the pile side.

\subsubsection{Influence of Number of Cycles on Pile-Soil Interaction.} In order to analyse the influence of the number of cycles on the displacement of the long spiral belled pile, the change of the pile displacement with the number of cycles during the forward and reverse loading process is plotted. As shown in Figure 10, the displacement of the long spiral belled pile decreases nonlinearly from the ground down. The horizontal load has a great influence on the displacement of the pile body in the depth range of $0-0.6 \mathrm{~m}$, but tends to zero at the lower part of the pile body. When the load is small, the pile displacement will not increase obviously although the load is applied. When the load increases further, the plastic deformation of the pile-soil system tends to develop, and the pile displacement increases faster.

It can be seen from Figure 10 that the deformation of pile top tends to be stable under the 4th-6th loading or unloading in the process of cyclic loading for 6 times. It can be seen that the number of cycles has little influence on the horizontal 


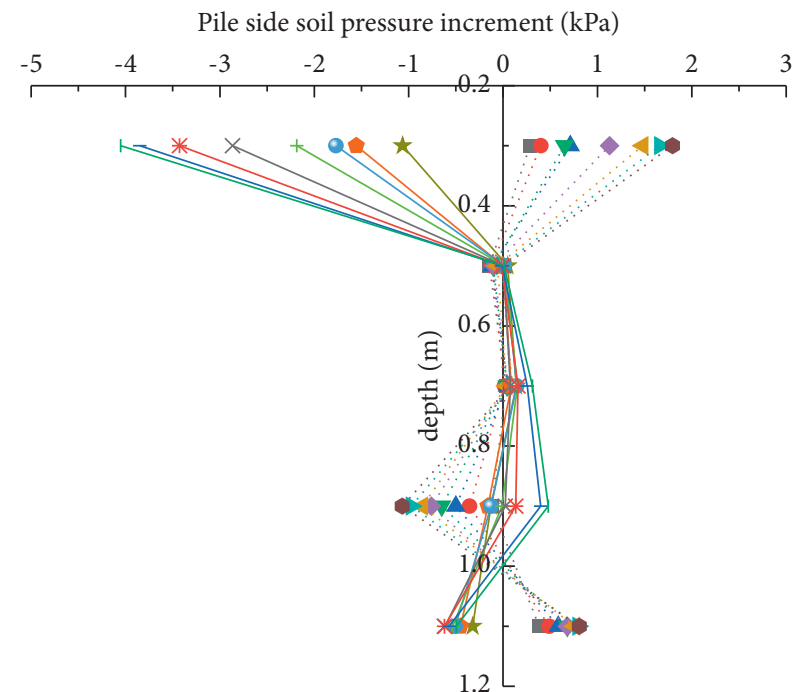

Back side of pile body Front side of pile body (compression-side)

\begin{tabular}{|c|c|}
\hline .. $0.53 \mathrm{kN}$ & $\star \quad 0.53 \mathrm{kN}$ \\
\hline - $\quad 0.63 \mathrm{kN}$ & $\multimap 0.63 \mathrm{kN}$ \\
\hline $0.73 \mathrm{kN}$ & $-\circ 0.73 \mathrm{kN}$ \\
\hline $0.83 \mathrm{kN}$ & $\multimap 0.83 \mathrm{kN}$ \\
\hline $0.93 \mathrm{kN}$ & $\leftarrow 0.93 \mathrm{kN}$ \\
\hline $1.03 \mathrm{kN}$ & $* 1.03 \mathrm{kN}$ \\
\hline $1.13 \mathrm{kN}$ & $-1.13 \mathrm{kN}$ \\
\hline $1.23 \mathrm{kN}$ & $-1.23 \mathrm{kI}$ \\
\hline
\end{tabular}

(a)
Pile side soil pressure increment $(\mathrm{kPa})$

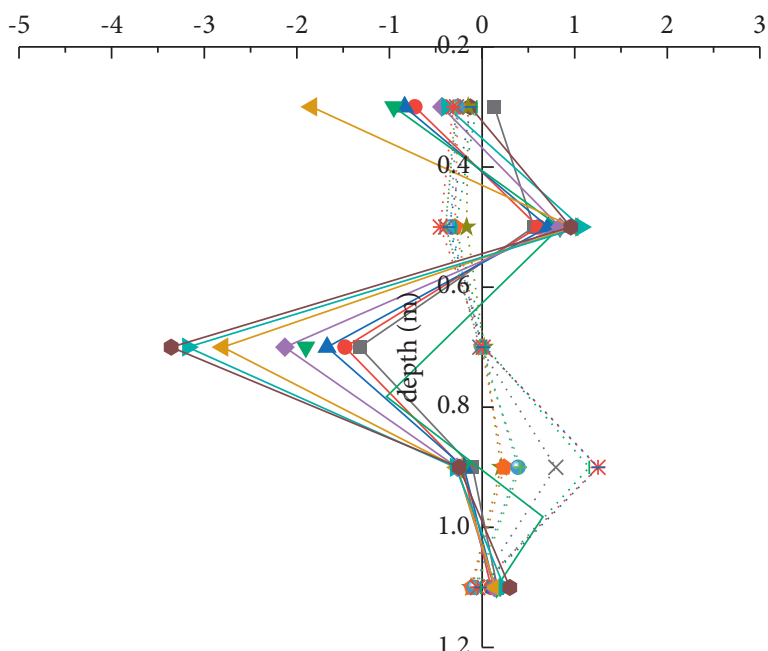

Back side of pile body (compression-side) Front side of pile body:

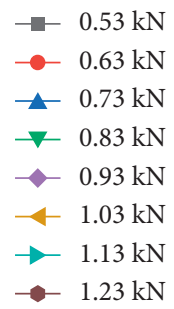

$\star 0.53 \mathrm{kN}$

- $0.63 \mathrm{kN}$

-. $0.73 \mathrm{kN}$

+. $0.83 \mathrm{kN}$

$\times \cdot 0.93 \mathrm{kN}$

*. $1.03 \mathrm{kN}$

-.. $1.13 \mathrm{kN}$

..... $1.23 \mathrm{kN}$

(b)

Figure 9: Soil pressure distribution on the front and back sides of the pile during cyclic reciprocating loading. (a) In forward loading process. (b) In reverse loading process.

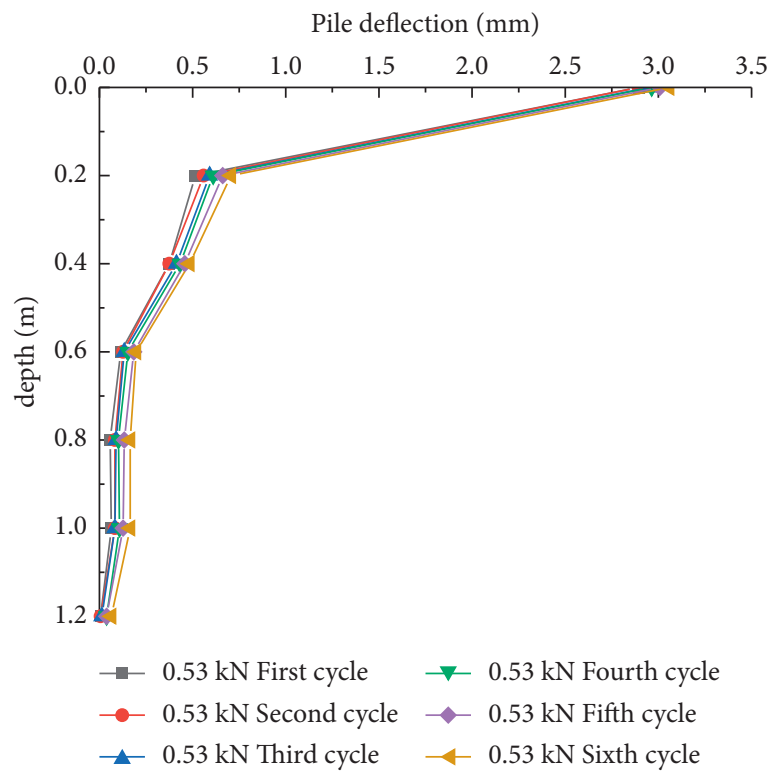

(a)

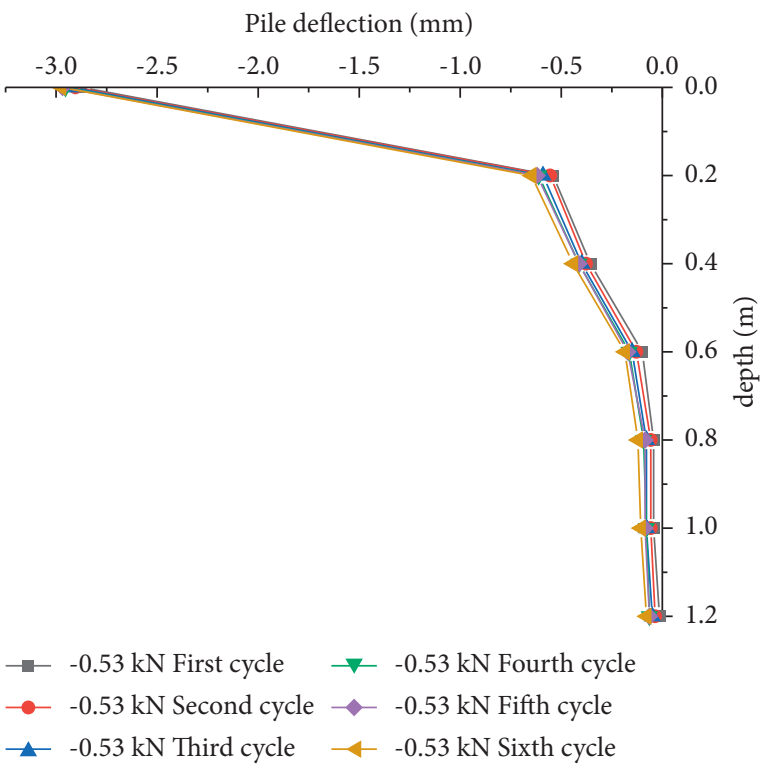

(b)

Figure 10: Continued. 


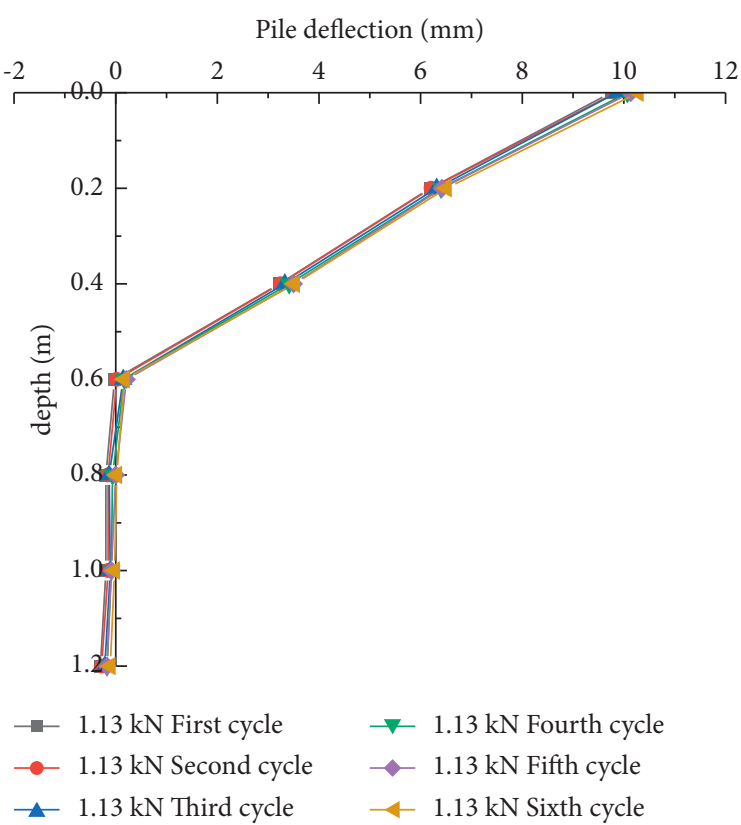

(c)

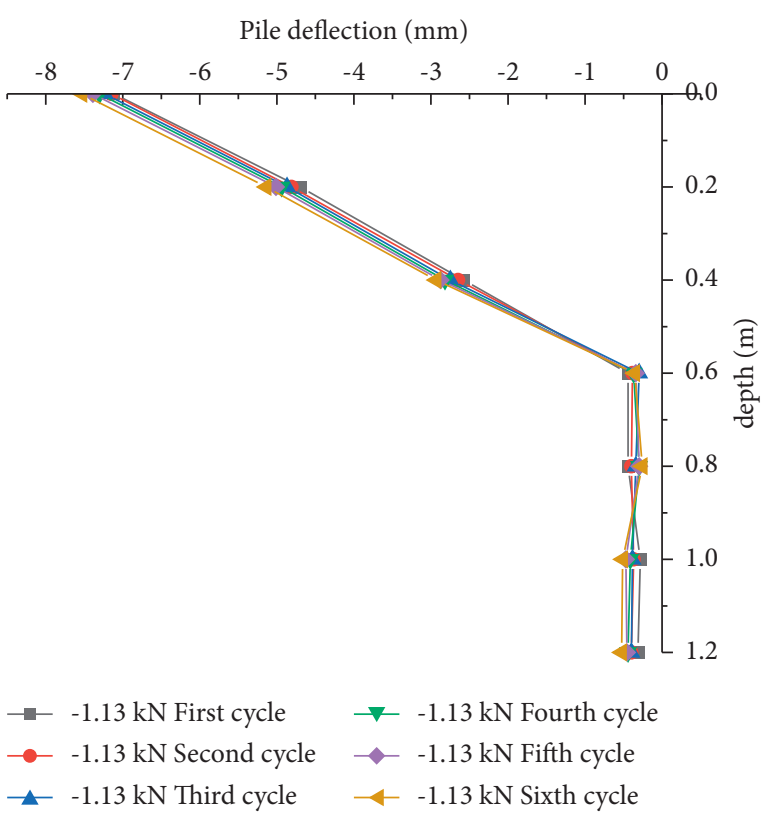

(d)

Figure 10: Deflection distribution of pile body under different cycles in the process of positive and negative loading. (a) $+0.53 \mathrm{kN}$. (b) $-0.53 \mathrm{kN}$. (c) $+1.13 \mathrm{kN}$. (d) $-1.13 \mathrm{kN}$.

displacement of pile top under the action of horizontal cyclic load.

In order to further compare the influence of cycle times on the bending moment of long spiral belled pile, Figure 11 shows the distribution of bending moment of LK3 test pile with the increase of cycle times under different load amplitude. When the load amplitude is small, the cycle times have little influence on the bending moment of pile body. When the load amplitude is large, the bending moment will fluctuate to a certain extent at a depth of $0.6 \mathrm{~m}$ with the increase of cycle times. It can be seen that the load amplitude has more obvious influence on the bending moment value of long spiral belled pile when the number of cycles is limited.

3.3. Damage Analysis. The skeleton curve is the peak point trajectory of the load-displacement curve of the test specimen under each cycle [28]. Through skeleton curve, the change trajectory of peak load in each horizontal cycle loading process can be determined, and the characteristics of different test piles in different loading stages can be determined, thus drawing the skeleton curves of six test piles under multi-stage cyclic loading, as shown in Figure 12.

The analysis of the skeleton curve shows that the whole deformation process of long spiral belled pile, belled pile, and straight pile with equal cross section under cyclic load can be divided into initial loading elastic stage, yield stage of bending moment deformation caused by stiffness change, and near failure limit stage.

(1) In the elastic stage of initial loading, with the increase of the horizontal load, the skeleton curve of the test pile shows a straight line with a large slope. At this stage, both the pile and the soil around the pile are in the elastic stage. Due to the existence of the enlarged head and the thread of the pile body, the pile and the soil around the pile have a better compaction effect. The linear slope of the skeleton curve of long spiral belled pile and belled pile in elastic stage is obviously larger than that of the straight pile. It can be seen that the existence of enlarged head and thread can effectively increase the bearing capacity.

(2) When the test pile reaches the yield stage, under the action of horizontal cyclic load, with the increase of load, the contact surface between the pile and the soil around the pile becomes loose, and the soil around the pile begins to degrade from top to bottom. As the strength of the soil around the pile decreases, the stress mode of the pile changes, gradually changing from Winkler foundation beam to cantilever beam $[29,30]$. As a result, the lateral stiffness of the pile decreases gradually, resulting in bending moment deformation, increase in pile displacement, reaching the yield stage, and the slope of the skeleton curve decreases gradually, showing a curve segment with a smaller slope.

(3) With the increase of the load approaching the ultimate failure load, the soil around the pile undergoes irreversible plastic deformation. When the ultimate load that the pile can bear is reached, the pile body will produce large displacement, which will lead to cracks in the pile body and gradually fracture failure.

Compared with the belled pile and the straight pile, the long spiral belled pile can undergo great deformation 


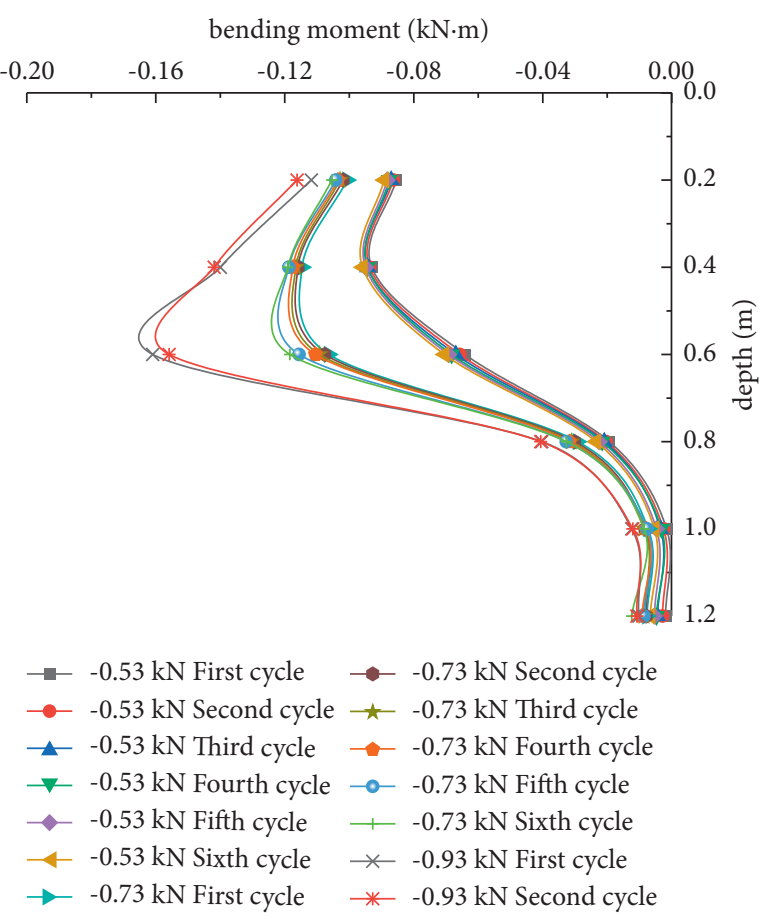

(a)

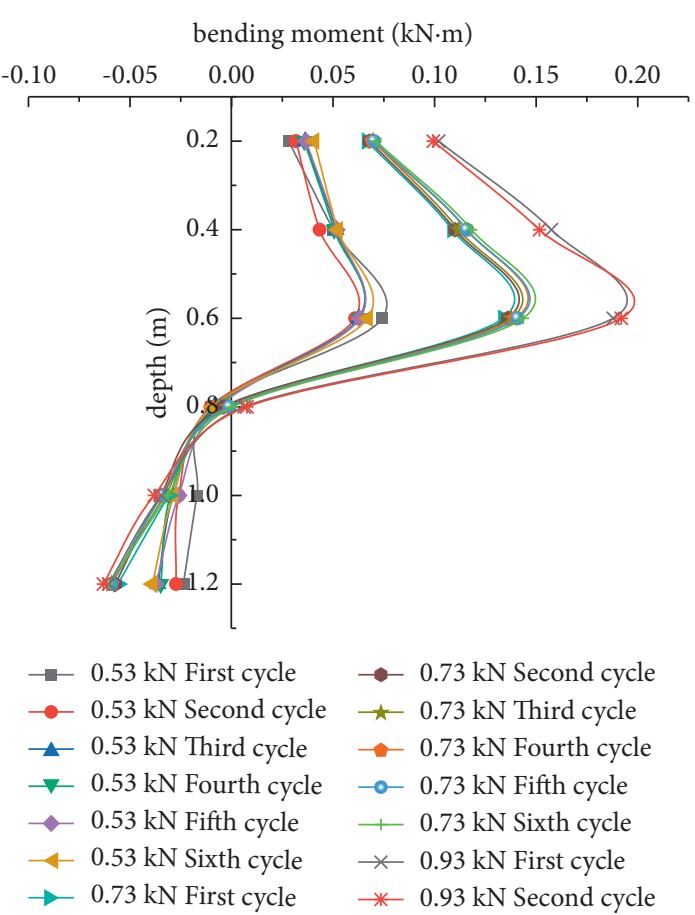

(b)

FIGURE 11: Bending moment distribution of LK3 under different load amplitude under reverse and forward loading. (a) In reverse loading process. (b) In forward loading process.

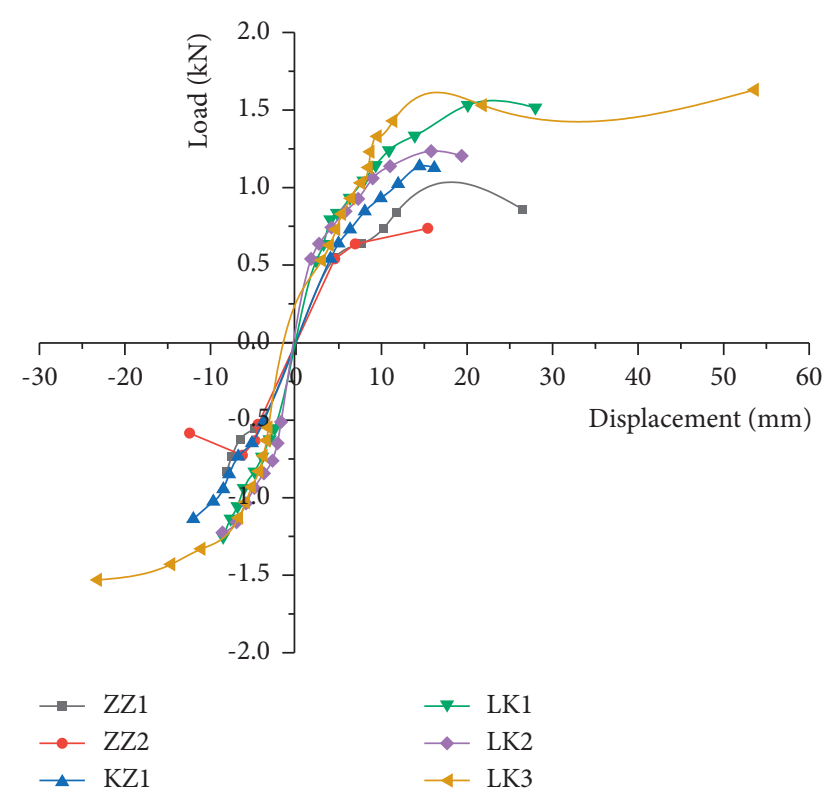

FIGURE 12: Skeleton curves of three kinds of test piles.

without significant reduction of bearing capacity under the same load before its failure, and the peak load increases significantly. Compared with straight pile and belled pile, the horizontal peak bearing capacity of long spiral belled pile is increased by $57.2 \%$ and $40.4 \%$, respectively. After reaching the limit load, the bearing capacity of long spiral belled pile does not decrease obviously. It shows that the bearing mechanism of long spiral belled pile with the same size is different from that of traditional straight pile and traditional belled pile under the condition of sea wind and wave load. The interaction between the threads of long spiral belled pile and the soil makes the special shape of threaded pile give better play to the shear strength of the soil around the pile, showing higher bearing capacity.

\subsection{Analysis of Energy Dissipation Characteristics under Horizontal Cyclic Load}

3.4.1. Hysteretic Curve. Under the action of sea wind and wave load, the vibration effect is achieved by applying the forward and reverse static forces at the position of the test pile head. The hysteretic curve is used to reflect the deformation and energy dissipation capacity of the test pile, and the cumulative damage and energy dissipation of a single pile under horizontal cyclic load are quantitatively described according to the energy dissipation coefficient, as shown in Figure 13.

By comparing the hysteretic curves of long spiral belled pile, belled pile, and straight pile under different load levels in laboratory tests, it can be found that:

(1) The hysteretic ring shape of long spiral belled pile and belled pile is similar. In the early stage of loading, the hysteretic ring pinching effect of the two pile types is obvious, which is similar to s-shape, and the energy dissipation capacity is worse than that of the straight pile. When loading to the later stage, the hysteretic ring shape becomes full and the pinching phenomenon is improved to some extent. On the 


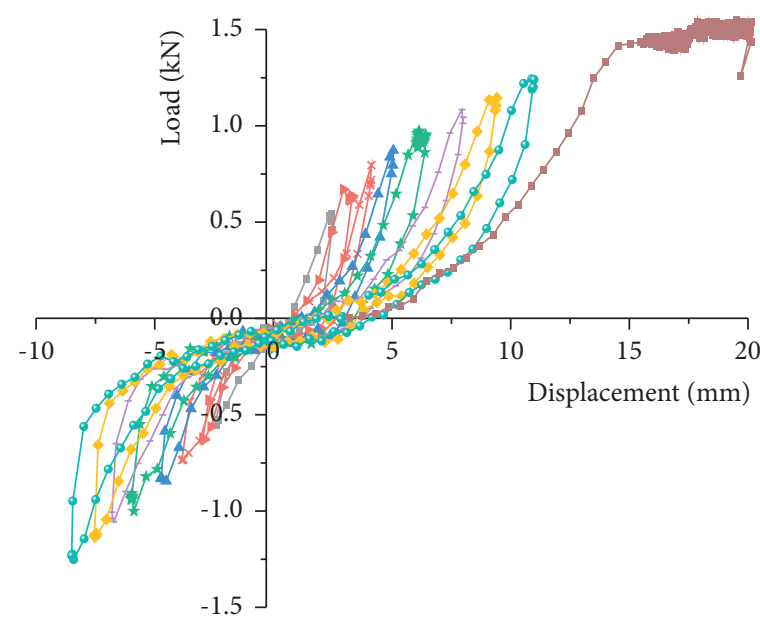

- $0.53 \mathrm{kN}$ First cycle

$\rightarrow \quad 0.63 \mathrm{kN}$ First cycle

$\leftarrow 0.73 \mathrm{kN}$ First cycle

$\_0.83 \mathrm{kN}$ First cycle

\# $0.93 \mathrm{kN}$ First cycle

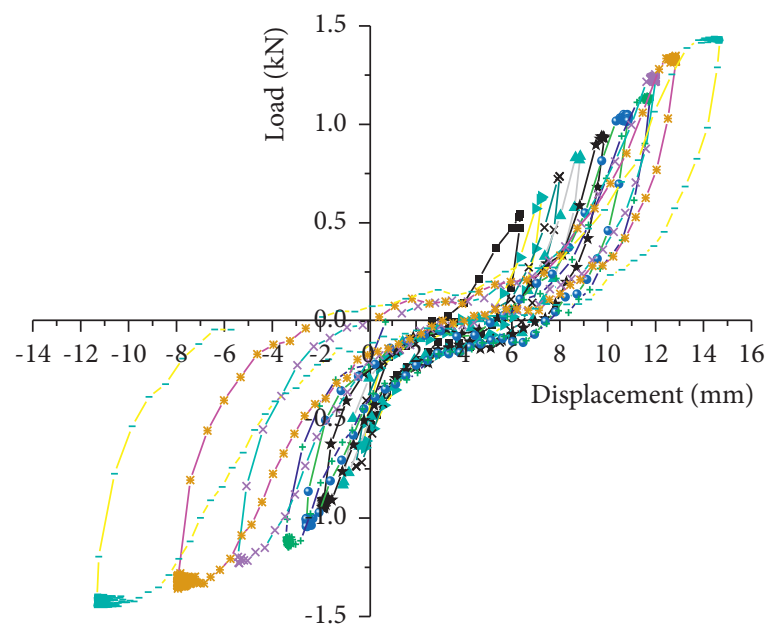

$\rightarrow 0.53 \mathrm{kN}$ First cycle

$\rightarrow \quad 0.63 \mathrm{kN}$ First cycle

$-0.73 \mathrm{kN}$ First cycle

$\triangle \quad 0.83 \mathrm{kN}$ First cycle

$\star 0.93 \mathrm{kN}$ First cycle (a)

\begin{abstract}
$1.03 \mathrm{kN}$ First cycle
$\rightarrow 1.13 \mathrm{kN}$ First cycle

$\because 1.23 \mathrm{kN}$ First cycle

$=1.33 \mathrm{kN}$ First cycle
\end{abstract}
$\because 1.03 \mathrm{kN}$ First cycle
$\longrightarrow-1.13 \mathrm{kN}$ First cycle
$\star 1.23 \mathrm{kN}$ First cycle
- $-1.33 \mathrm{kN}$ First cycle
- 1.43 kN First cycle

(c)

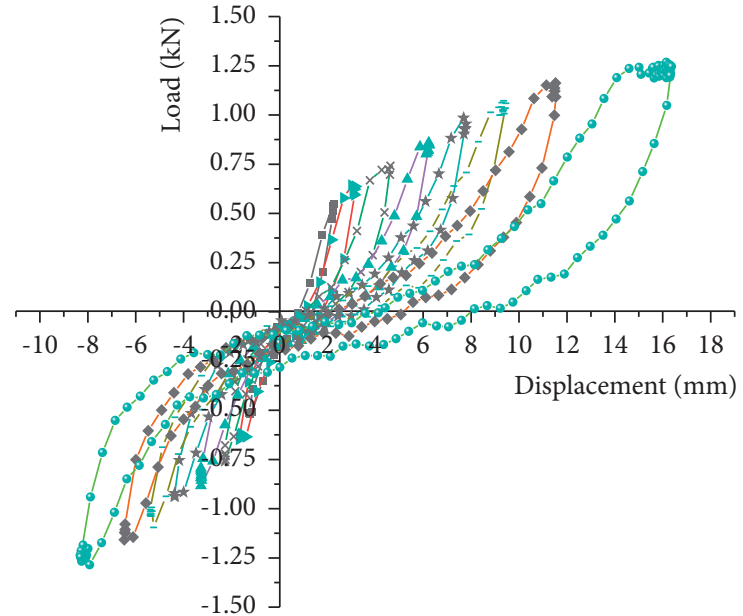

$\multimap 1.23 \mathrm{kN}$ First cycle

$\rightarrow 0.83 \mathrm{kN}$ First cycle

$\rightarrow 1.13 \mathrm{kN}$ First cycle

$\star \quad 0.73 \mathrm{kN}$ First cycle

- $1.03 \mathrm{kN}$ First cycle

$\rightarrow-0.63 \mathrm{kN}$ First cycle

* $0.93 \mathrm{kN}$ First cycle

(b)

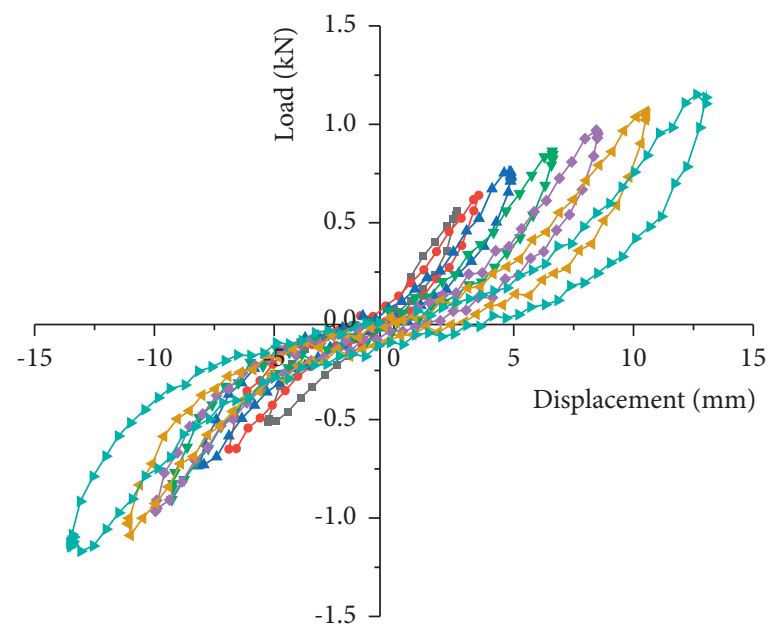

$\rightarrow 0.53 \mathrm{kN}$ First cycle
$\rightarrow 0.63 \mathrm{kN}$ First cycle
$-0.73 \mathrm{kN}$ First cycle
$\rightarrow 0.83 \mathrm{kN}$ First cycle

$\longrightarrow 0.93 \mathrm{kN}$ First cycle

$\longleftarrow 1.03 \mathrm{kN}$ First cycle

$\rightarrow-1.13 \mathrm{kN}$ First cycle

(d)

Figure 13: Continued. 


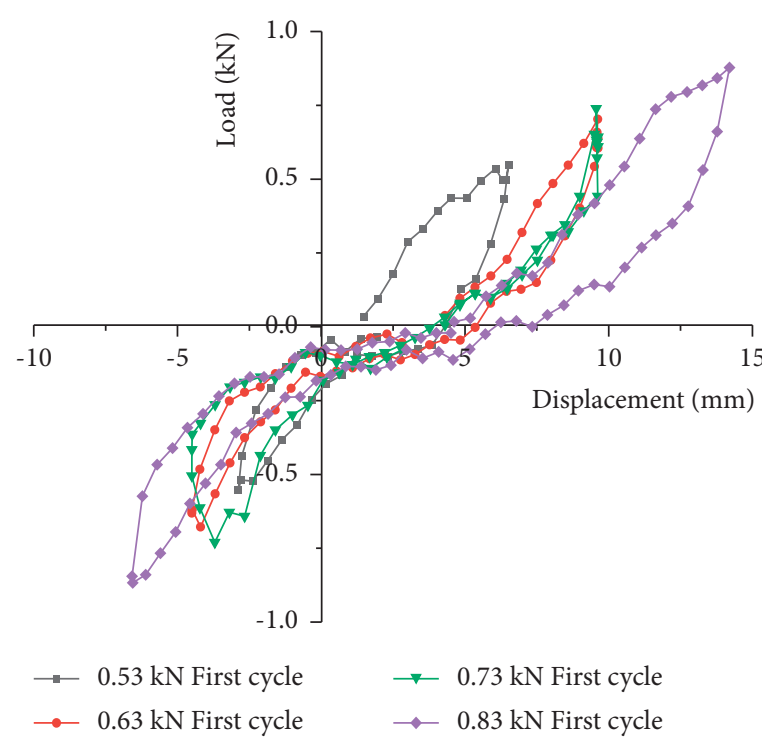

(e)

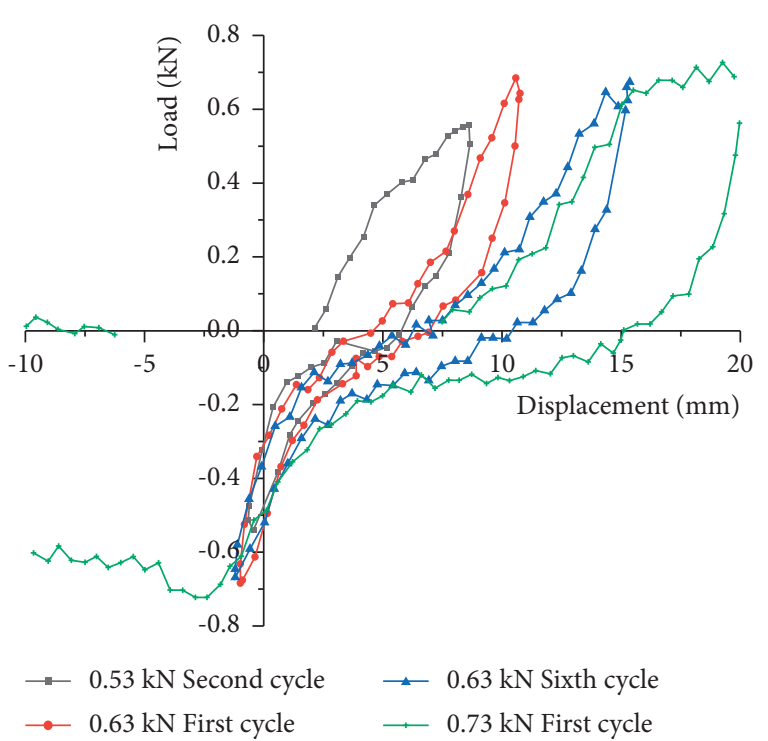

(f)

Figure 13: Hysteretic loop morphology under different load levels. (a) LK1. (b) LK2. (c) LK3. (d) KZ1. (e) ZZ1. (f) ZZ2.

whole, compared with the straight pile and the belled pile, the long spiral belled pile has better energy dissipation capacity and better stability.

(2) In the reverse loading stage, the long spiral bottomexpanding pile and the bottom-expanding pile have good bearing capacity and symmetrical hysteretic loop shape, while the straight pile under the action of horizontal cyclic load has unstable and irregular hysteretic loop shape, and cannot form a relatively symmetrical closed loop at the early loading stage, showing poor horizontal bearing capacity.

(3) By comparing the hysteretic cycle morphology of the long spiral bottom-expanding pile at the early, middle, and late loading stages, it can be found that under the loading condition of $0.53 \mathrm{kN}$, the hysteretic cycle morphology does not change significantly with the increase of the number of cycles; When the load level is higher, the number of cycles has a certain effect on the hysteretic performance of the test pile.

In order to analyse the influence of cycle times on hysteretic ring shape of long spiral belled pile under horizontal cyclic loading, taking LK2 as an example, the change process of cycle times on hysteretic ring shape under multistage cyclic loading is plotted, as shown in Figure 14.

By comparison, it can be found that when the load level is large, the hysteretic behavior of long spiral belled pile will be improved with the increase of cycle times. At the early loading stage, the morphology of the hysteretic loops in the 1 st to 6 th cycles basically overlapped. With the change of the pile top load, the hysteretic loops extended in the direction of displacement axis, and the area of the hysteretic loops gradually increased, while the overlap of the hysteretic loops gradually decreased under the same load level, so the long spiral belled pile will show a stable trend under the cyclic load of sea wind and waves.
3.4.2. Energy Consumption Characteristics. The energy dissipation capacity of test pieces under horizontal cyclic loads is usually measured by the area of hysteretic loops. In Code for Seismic Test Methods for Buildings [31], the energy dissipation coefficient $E$ is used to conduct a quantitative analysis of the energy dissipation characteristics of test pieces. The calculation formula is shown in equation (1). The higher the value of $E$ is, the better the energy dissipation efficiency of the test pile is.

$$
E=\frac{S_{A B C}+S_{C D A}}{S_{O B E}+S_{O D F}} .
$$

In the formula, $E$ is the energy dissipation coefficient of the test pile under horizontal loading; $S_{A B C}$ and $S_{C D A}$ represent the area surrounded by hysteresis loop and displacement axis in the process of forward and reverse loading expressed, respectively; $S_{O B E}$ and $S_{O D F}$ represent the triangle area surrounded by peak point and displacement axis in forward and reverse loading process, respectively. The calculation diagram [31] is shown in Figure 15.

Through calculation, the energy dissipation coefficient of each test pile under different load levels was obtained, and the trend diagram of the energy dissipation coefficient of a single pile under horizontal load changing with the number of loading cycles is further drawn, as shown in Figure 16.

(1) Under the action of horizontal cyclic load, the energy dissipation coefficient of each test pile first gradually decreases and then tends to be stable with the increase of load and cycle times, which has certain continuity. Compared with straight pile and belled pile, the attenuation rate of energy dissipation coefficient of long spiral belled pile is relatively slow and its bearing capacity is higher during cyclic loading. Therefore, the long spiral belled pile has 

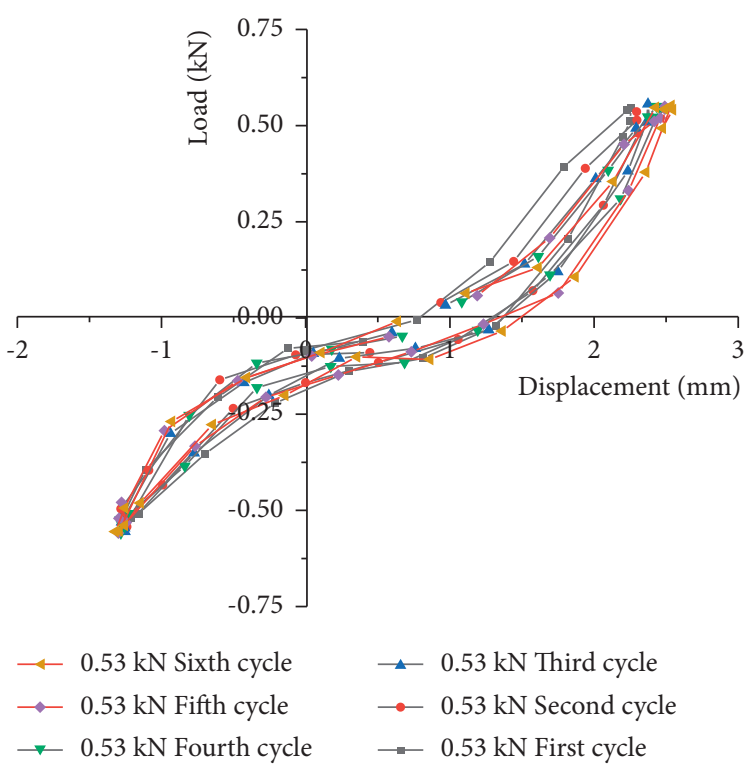

(a)
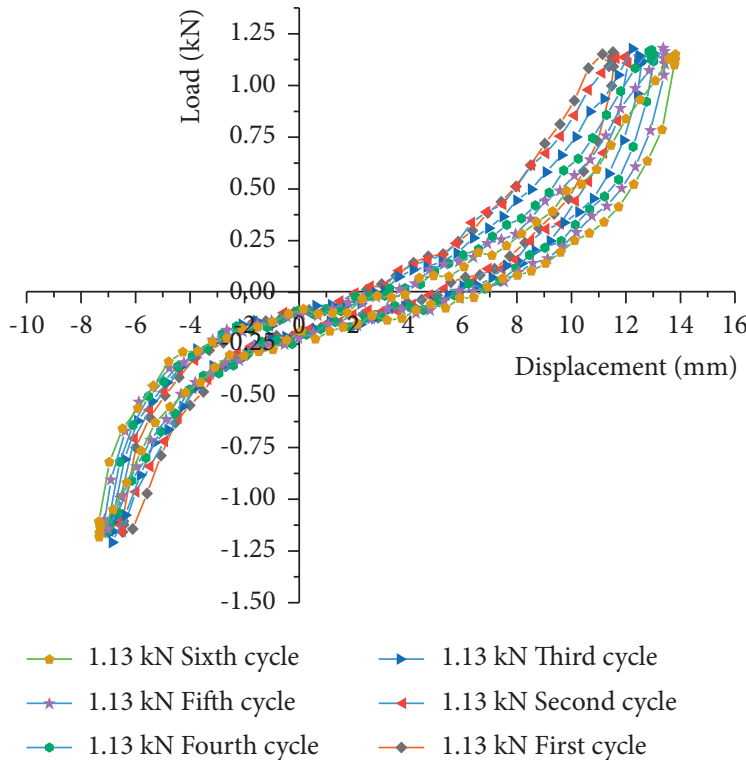

(c)
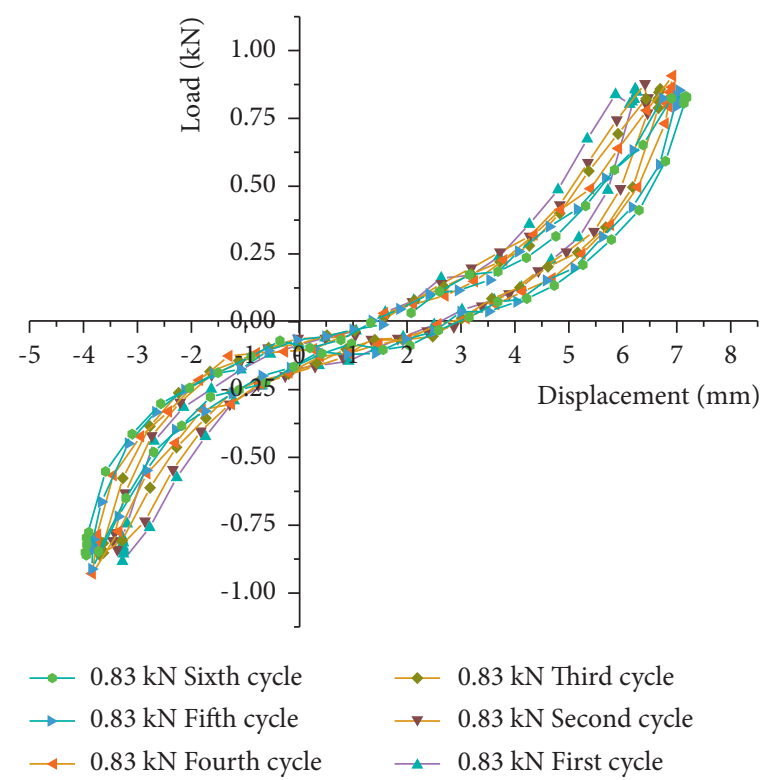

(b)
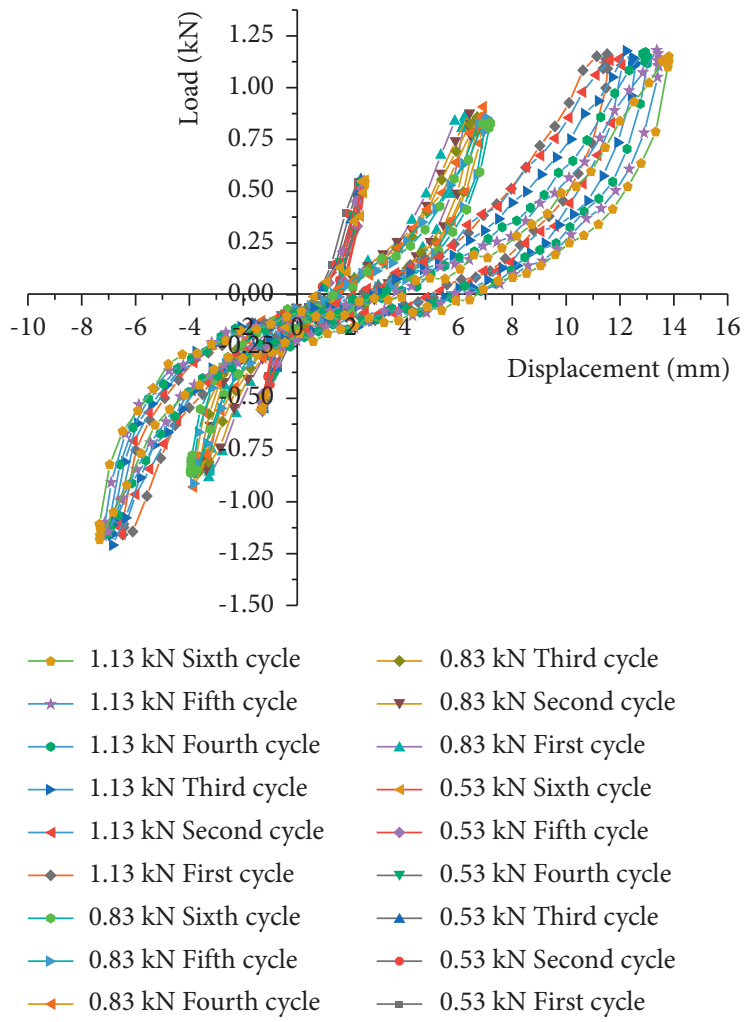

(d)

FiguRE 14: Influence of cycle number on hysteretic cycle shape under different load levels. (a) $\pm 0.53 \mathrm{kN}$. (b) $\pm 0.83 \mathrm{kN}$. (c) $\pm 1.13 \mathrm{kN}$. (d) View the situation as a whole.

better energy dissipation capacity and better bearing capacity in the field of offshore wind piles.

(2) At the initial stage of the load application, under the reciprocating action of horizontal cyclic load, both the pile and the soil around the pile are in the elastic stage, the soil around the pile is repeatedly squeezed, and the compactness is increasing. The ability of the pile and soil around the pile to absorb energy is good. With the continuous increase of load, the squeezing effect of cyclic load on the soil around the pile is weakened, and the pile-soil interface is gradually separated. The soil around the pile degenerates and gradually fails, the bending moment of the pile body increases and cracks are produced, the energy dissipation capacity of the pile 


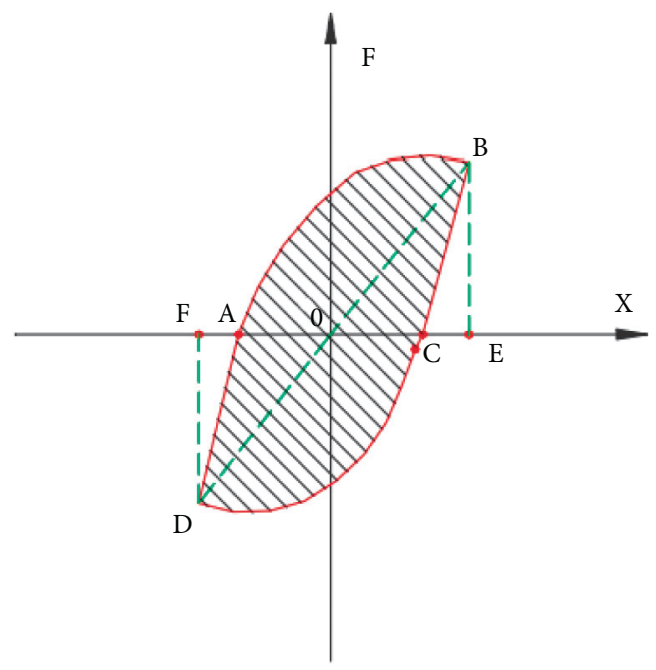

FIGURE 15: Load-deformation hysteresis curve.

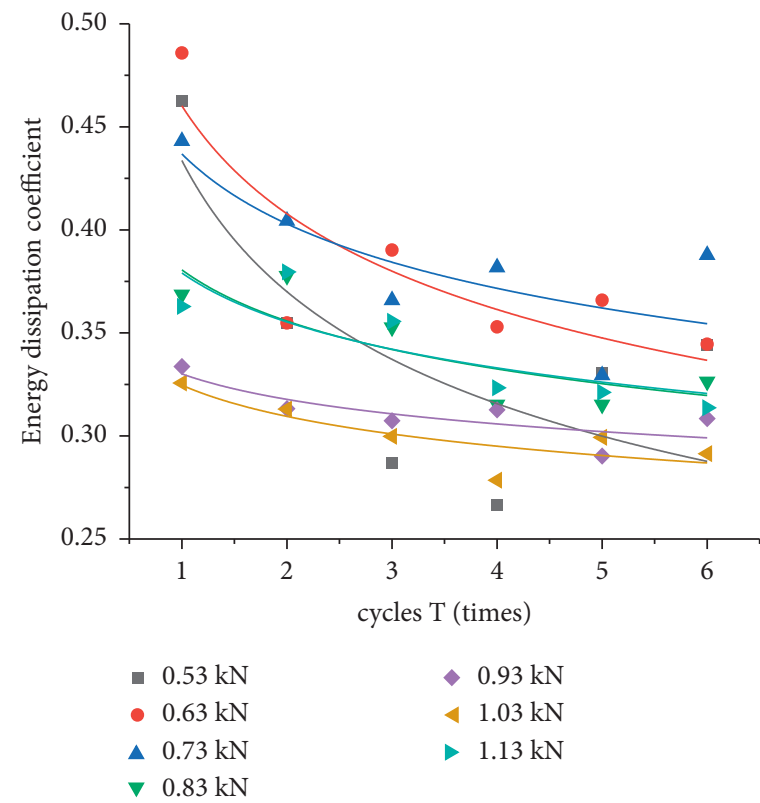

(a)

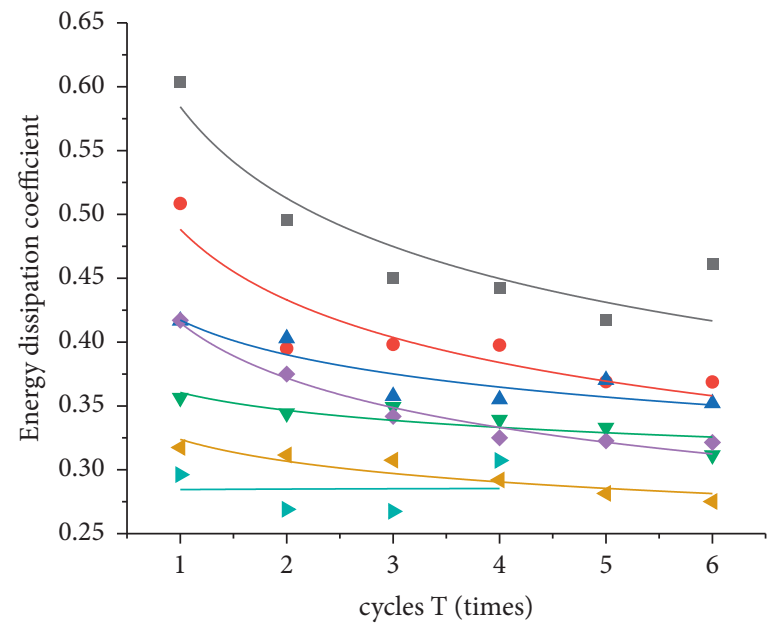

- $0.53 \mathrm{kN}$

- $0.63 \mathrm{kN}$

A $0.73 \mathrm{kN}$

$\checkmark 0.83 \mathrm{kN}$
- $0.93 \mathrm{kN}$

4 $1.03 \mathrm{kN}$

- $1.13 \mathrm{kN}$

(b)

FIgUre 16: Continued. 


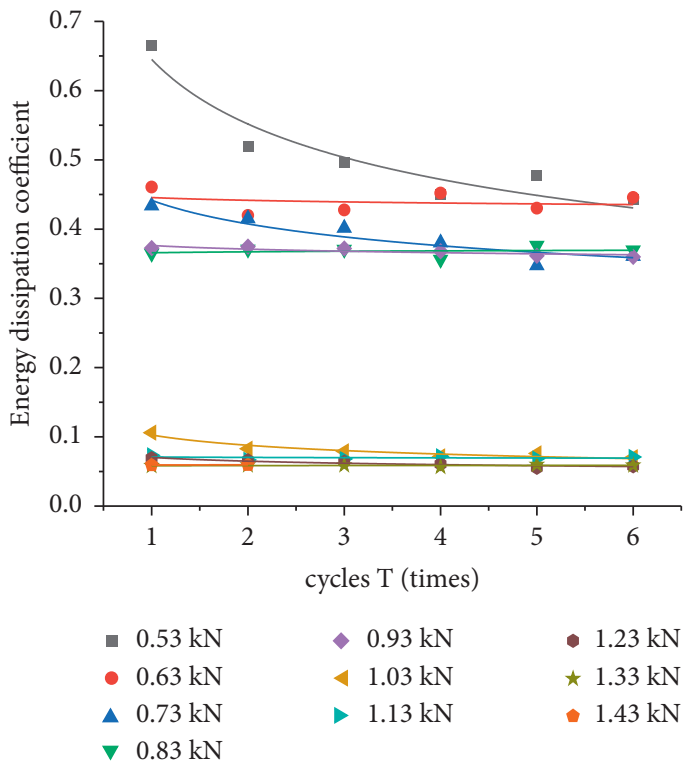

(c)

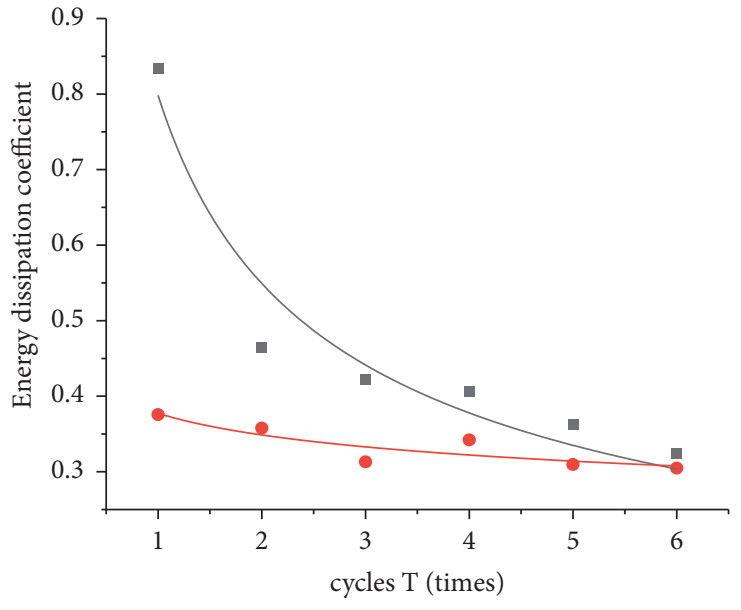

$0.53 \mathrm{kN}$

- $0.63 \mathrm{kN}$

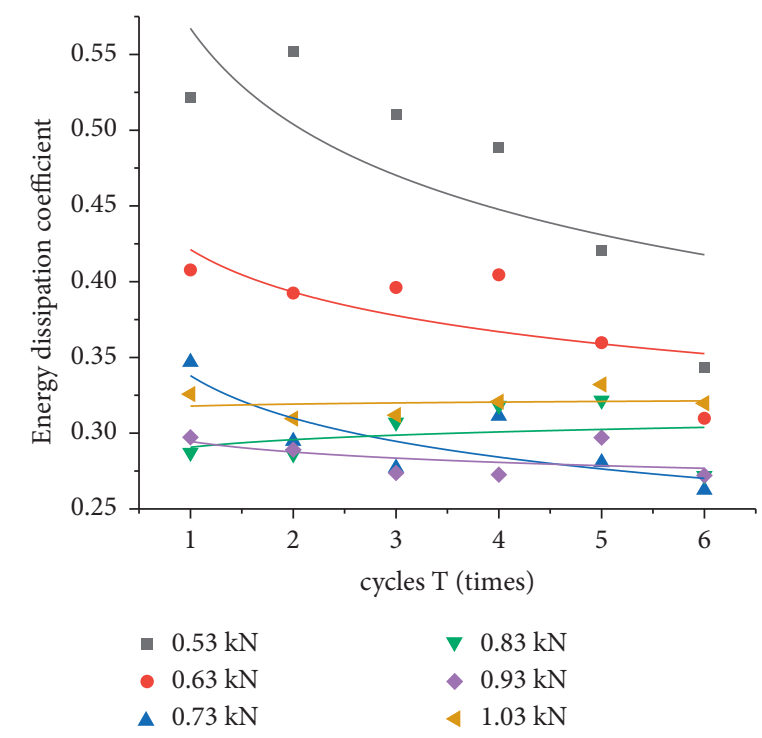

(d)

(e)

Figure 16: Relationship between energy dissipation coefficient and cycle times. (a) LK1. (b) LK2. (c) LK3. (d) ZZ1. (e) KZ1.

body weakens, and the energy dissipation coefficient gradually stabilizes. At this time, the influence of cycle times on the energy dissipation characteristics of the test pile is not significant, and the curve presents an approximate straight line.

Compared with straight pile and belled pile, the horizontal bearing capacity of long spiral belled pile is significantly improved. Therefore, under the same level of load, the energy dissipation capacity of long spiral belled pile is better than belled pile and straight pile, and it has better stability.

3.4.3. Prediction Model of Energy Consumption Coefficient. In order to explore the variation law of energy dissipation characteristics of long spiral belled pile with cycle times under different load levels of sea wind and waves, the variation trend of energy dissipation coefficient with cycle times under different load amplitude is quantitatively analysed, and then power function is used to fit it, and the fitting accuracy is high, as shown in Figure 17.

It can be seen from Figure 17 that the energy dissipation coefficient of the three long spiral belled piles varies in a generally consistent trend under horizontal cyclic loads (six cycles of the same grade load). Under the same load level, the energy dissipation coefficient $E$ decreases as a power function with the increase of the cyclic coefficient $T$, and the power function formula is as follows:

$$
E=a T^{b}(0<a<1, b<0)
$$




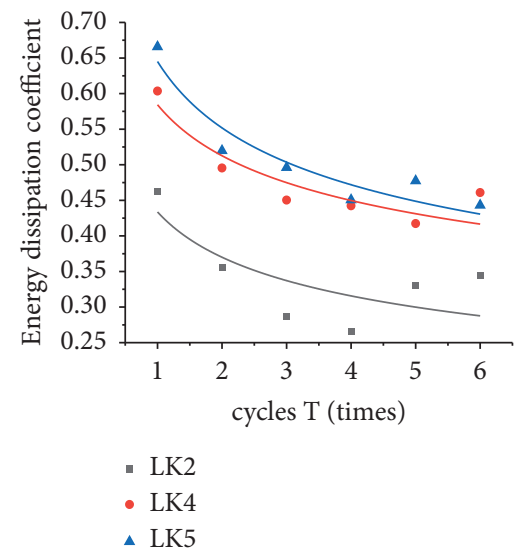

(a)

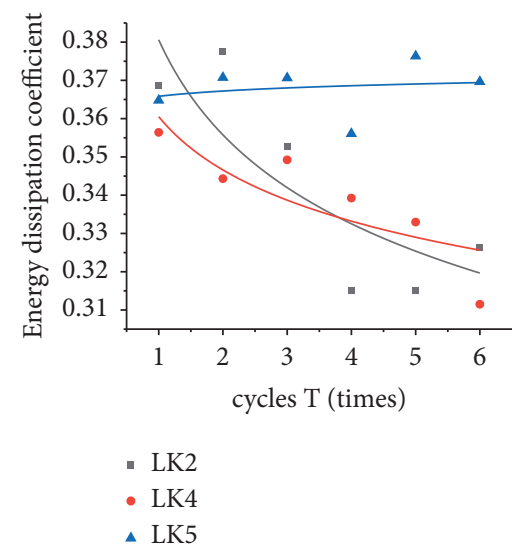

(d)

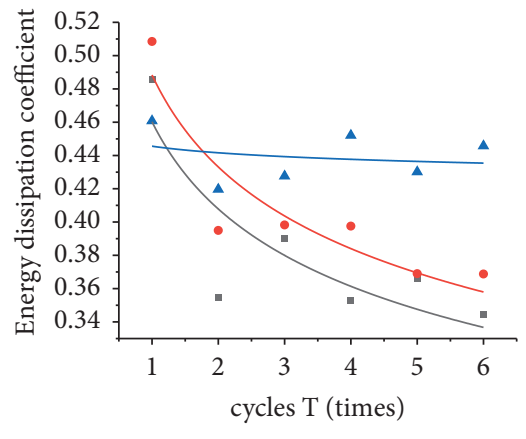

- LK2
- LK4
- LK5

(b)

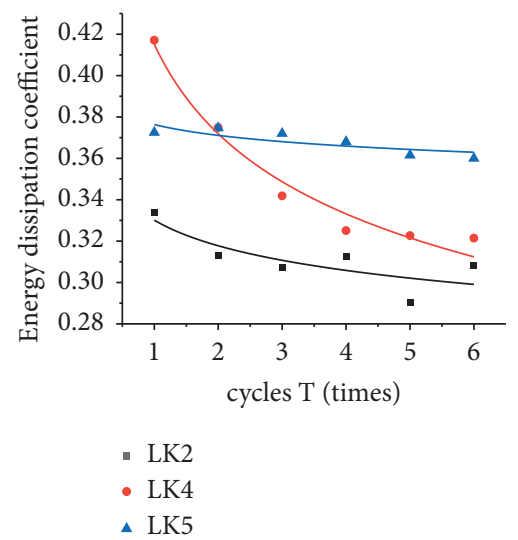

(e)

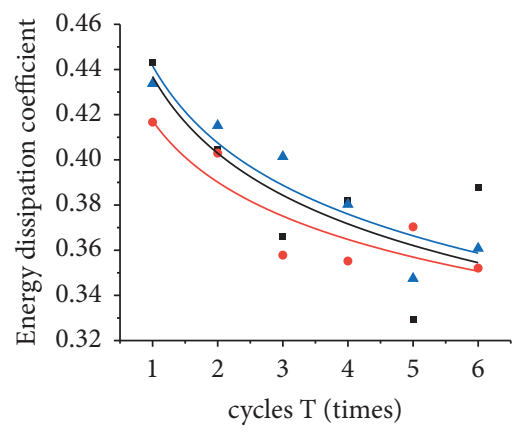

- LK2

- LK4

$\triangle$ LK5

(c)

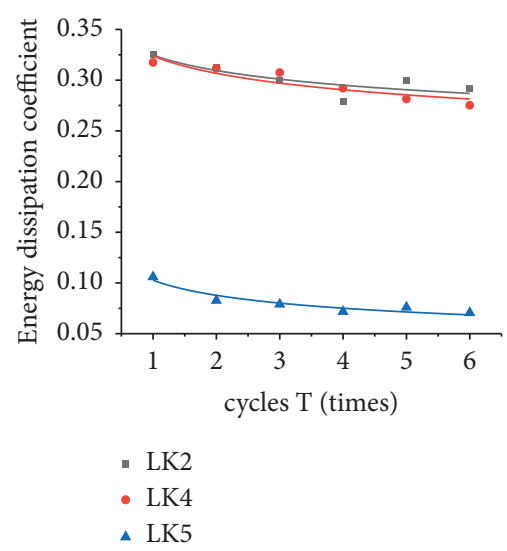

(f)

FIGURE 17: Relationship between energy dissipation coefficient of long spiral belled pile and cycle times under various loads. (a) $\pm 0.53 \mathrm{kN}$. (b) $\pm 0.63 \mathrm{kN}$. (c) $\pm 0.73 \mathrm{kN}$. (d) $\pm 0.83 \mathrm{kN}$. (e) $\pm 0.93 \mathrm{kN}$. (f) $\pm 1.03 \mathrm{kN}$.

Parameters $a$ and $b$ of power function reflect the decreasing rate of energy dissipation coefficient $E$ with the number of cycles $T$ under various amplitudes of load. With the increase of load, parameter $|a|$ gradually decreases, $|b|$ gradually decreases and tends to zero, the curve gradually changes from steep to flat, and the decreasing rate of energy dissipation coefficient gradually slows down from fast to flat at last. When the test pile is in different stages (elasticity, yield, and failure), according to the variation law of energy dissipation coefficient of long spiral belled pile with the number of cycles, the suggested value range of power function model parameters in different failure stages is given, as shown in Table 5.

According to the statistics of cumulative damage degree of long spiral belled pile under different load levels, the cumulative hysteretic energy consumption is used to reflect the damage degree of the specimen. The relationship between the parameters $a$ and $b$ of the power function model and the load amplitude is shown in Figure 18. The power function parameter $a$ decreases with the increase of the load amplitude, while the parameter $b$ increases with the increase of the load amplitude and tends to zero gradually. There is a good linear relationship between the model parameters and the load amplitude.
TABLE 5: Range of power function parameters in different loading stages.

\begin{tabular}{lcc}
\hline Stage & $\begin{array}{c}\text { Power function } \\
\text { parameter } a \text { range } \\
\text { interval }\end{array}$ & $\begin{array}{c}\text { Power function } \\
\text { parameter } b \text { range } \\
\text { interval }\end{array}$ \\
\hline Elastic stage & $(0.35,0.70)$ & $(-0.30,-0.10)$ \\
Yield stage & $(0.20,0.35)$ & $(-0.10,-0.05)$ \\
Failure stage & $(0,0.20)$ & $(-0.05,0)$ \\
\hline
\end{tabular}

In order to further study the relationship between the energy dissipation coefficient of long spiral belled pile and the number of cycles, a long spiral belled pile (Lk4) was subjected to single-stage cyclic loading. The schematic diagram of loading mode is shown in Figure 5(b), and the results are shown in Figure 19.

According to the distribution chart of Lk4 energy dissipation coefficient with the number of cycles, combined with the relationship between the energy dissipation coefficient and the number of cycles of other test piles, it is found that in the early stage of loading, the increase of the number of cycles will cause the energy dissipation coefficient to drop sharply until it tends to be stable at last, which indicates that the cumulative damage of long spiral belled pile in short- 


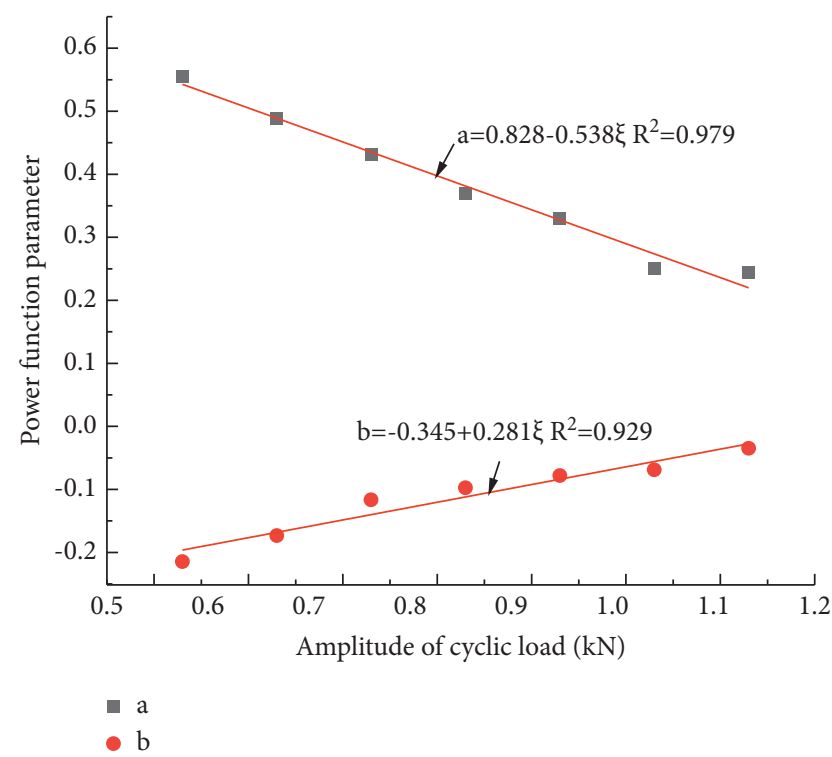

FIGURE 18: Variation law of power function model parameters with load amplitude.

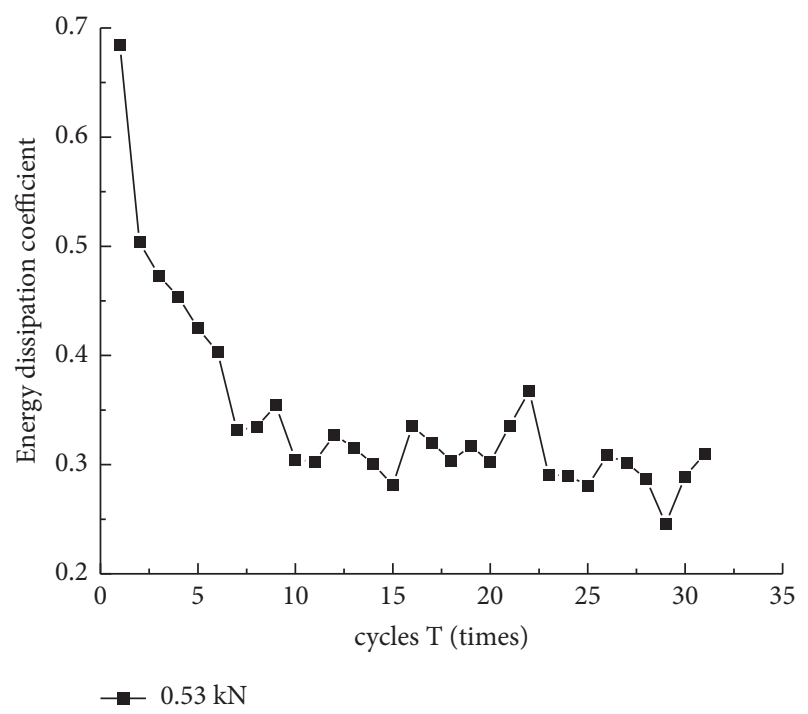

FIGURE 19: The relation between energy dissipation coefficient of LK4 and number of cycles.

term cycle is obvious, along with the change of circulation coefficient of energy dissipation coefficient, which has a short-term effect.

3.4.4. Verification of the Model. In order to verify the validity of the power function prediction model and the rationality of the power function parameters, the first six cyclic loading test results of LK4 under single-stage cyclic load $(0.53 \mathrm{kN})$ were taken for verification, and the results are shown in Figure 20.

As can be seen from Figure 20, under the horizontal cyclic load of $\pm 0.53 \mathrm{kN}$ for LK4, with the increase of the number of cycles, the energy dissipation coefficient $E$ presents a power function distribution. The power function

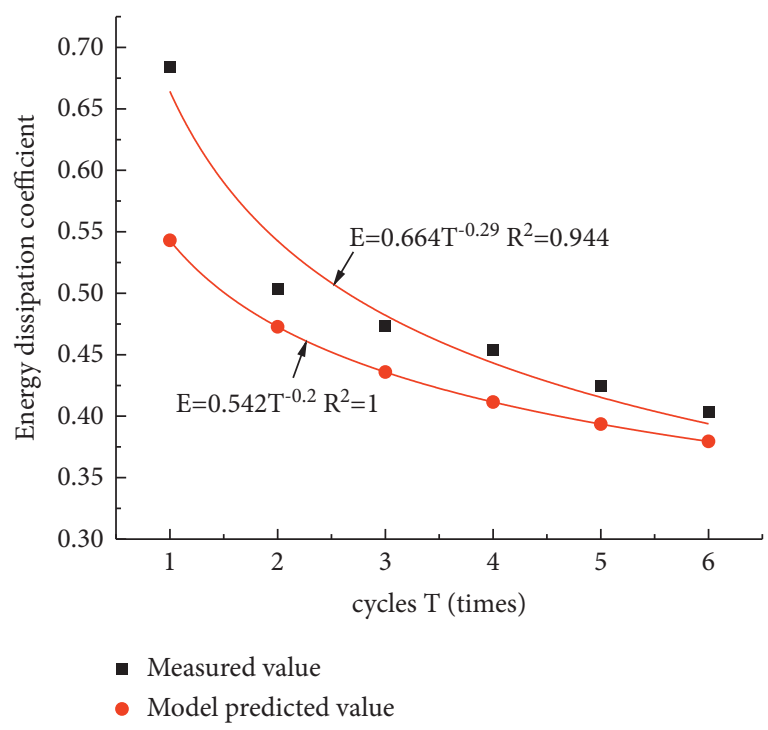

Figure 20: Comparison of energy dissipation coefficient model prediction and measured measurement at $\pm 0.53 \mathrm{kN}$ for LK4.

fitting results have a high accuracy, and the parameters $a$ and $b$ are within the recommended value range of the elastic stage. By comparing the predicted results of power function model with the measured values of test piles, the predicted results of energy dissipation coefficient are lower than the measured ones, with a small error of about $22 \%$, which is relatively close to the measured values. Therefore, it can be seen that the power function model can well predict the energy dissipation characteristics of long spiral enlarged bottom piles under the action of horizontal cyclic load.

\section{Conclusion}

A group of the horizontal pseudo-static cyclic tests have been conducted for the offshore pile. Then, the cumulative damage and energy dissipation characteristics of the long spiral belled piles have been investigated. Furthermore, a power function prediction model of energy dissipation coefficient under multi-stage cyclic loads is put forward. Through the distribution of disturbance, bending moment, and Earth pressure around the pile, the influence of the cyclic load amplitude and cycle times on pile-soil interaction is discussed. According to the testing results, the following conclusions are drawn:

(1) As compared with the straight pile and belled pile, the interaction between the long spiral belled pile and the surrounding soil is stronger due to the existence of threads and enlarged heads. Meanwhile, the special pile structure can enhance the shear strength and of the pile and its surrounding soil. Its peak horizontal bearing capacity is increased by $57.2 \%$ and $40.4 \%$, respectively, in contrast with that of the straight pile and belled pile.

(2) The horizontal displacement of long spiral belled pile is mainly concentrated in the upper part $(\mathrm{L} / 2)$ under the cyclic load. There presents a bending moment 
curve change of first increasing and then decreasing with the increase of the pile depth. The maximum bending moment point of pile coincides with the zero point of horizontal displacement of the pile (at 9 times of the pile diameter), and the pile body breaks at this position. The disturbance range of soil around pile is 2-4 times of the pile diameter. The soil pressure around the pile changes significantly with the depth. With the growth in depth, the soil pressures on the side of the pile decrease. In the horizontal direction, the maximum influence range of the soil is located near the top surface of the pile body. With the increase of the pile depth, the influence range gradually decreases and presents an approximate conical shape.

(3) The amplitude of cyclic load has a significant impact on the bearing characteristics of the long spiral belled pile. Under cyclic load, the soil around the pile is squeezed by the test pile. As cyclic load amplitude increases, the soil around the pile undergoes irreversible plastic deformation, which leads to the gradual increase of pile displacement. As a result of the limited number of cycles, it seems that the number of cycles has little influence on the displacement of the pile top and the bending moment of the pile body. Under large loading conditions, the displacement of the pile top and bending moment of the pile body show a small increase range by the increase of cycle times. In contrast with the limited cycle times, the load amplitude is inclined to significantly affect the bearing characteristics of the long spiral belled pile.

(4) At the initial stage of loading process, both the long spiral belled pile and its surrounding soil are in the elastic deformation stage. The pinch effect of hysteresis loop of the long spiral belled pile is obvious, which is S-shaped. As the loading process continues, the shape of hysteresis loop turns to full and symmetrical. When compared with the straight pile and belled pile, long spiral belled pile shows better energy dissipation capacity and stability, and the order of energy dissipation capacity is: long spiral belled pile $>$ belled pile $>$ straight pile.

(5) The novel power function model can well reflect the cumulative damage characteristics of long spiral belled piles under horizontal cyclic load. The parameters of power function model have a good linear relationship with load amplitude. Since the load amplitude increases, parameter a gradually decreases, while parameter $b$ gradually increases, and finally tends to zero. Owing to the fact that the testing pile has experienced different failure stages (elasticity, yield, and failure) during the whole loading process, the reduction rate of energy dissipation coefficient gradually decreases from fast to flat. Then, the suggested value range of power function model parameters in different failure stages is put forward. The calculation example shows that the prediction model has good applicability.
(6) The energy dissipation coefficient of long spiral belled pile has certain continuity with the increase of load amplitude under horizontal cyclic load originated from offshore wind and wave. Comparing it with straight pile and belled pile, the attenuation rate of energy dissipation coefficient is relatively slow. It deems that long spiral belled pile has preferable bearing capacity and energy dissipation capacity. These advantages are beneficial to the application and popularization of long spiral belled pile in marine structures.

\section{Data Availability}

All the data in this paper are checked, which are obtained from tests in this study, and no other data were used to support this study.

\section{Conflicts of Interest}

The authors declare that there are no conflicts of interest regarding the publication of this paper.

\section{Acknowledgments}

This research was supported by the National Natural Science Foundation of China (Nos. 52168045 and 51668002).

\section{References}

[1] S. N. Rao and K. M. Rao, "Behaviour of rigid piles in marine clays under lateral cyclic loading," Ocean Engineering, vol. 20, no. 1, pp. 281-293, 1993.

[2] S. Basack and R. D. Purkayastha, "Behaviour of single pile under lateral cyclic load in marine clay," Asian Journal of Civil Engineering, vol. 8, no. 4, pp. 443-458, 2007.

[3] M. Achmus, Y.-S. Kuo, and K. Abdel-Rahman, "Behavior of monopile foundations under cyclic lateral load," Computers and Geotechnics, vol. 36, no. 5, pp. 725-735, 2009.

[4] W. Liao, J. Zhang, J. Wu, and K. Yan, "Response of flexible monopile in marine clay under cyclic lateral load," Ocean Engineering, vol. 147, no. 1, pp. 89-106, 2018.

[5] D. Kong, Y. Liu, M. Deng, and X. Zhao, "Analysis of influencing factors of lateral soil resistance distribution characteristics around monopile foundation for offshore wind power," Applied Ocean Research, vol. 97, no. 1, Article ID 102106, 2020.

[6] C. Niemann, C. O’Loughlin, Y. Tian, M. J. Cassidy, and O. Reul, "Pile groups subjected to lateral cyclic loading-a comparison of $1 \mathrm{~g}$ and centrifuge model tests," in Proceedings of the 17th European Conference on Soil Mechanics and Geotechnical Engineering, pp. 1-8, Reykjavik, Iceland, September 2019.

[7] C. Niemann, C. O’Loughlin, Y. Tian, M. Cassidy, and O. Reul, "Response of pile groups in sand due to lateral cyclic loading," International Journal of Physical Modelling in Geotechnics, vol. 19, no. 6, pp. 318-330, 2019.

[8] S. Basack, "A technical note on development and performance study of a set-up for imparting lateral cyclic load on piles," Marine Georesources \& Geotechnology, vol. 27, no. 4, pp. 322-341, 2009. 
[9] S. Basack, "Design recommendations for pile subjected to cyclic load," Marine Georesources \& Geotechnology, vol. 33, no. 4, pp. 356-360, 2015.

[10] S. Basack and S. Nimbalkar, "Measured and predicted response of pile groups in soft clay subjected to cyclic lateral loading," International Journal of Geomechanics, vol. 18, no. 7, Article ID 04018073, 2018.

[11] R. P. Chen, C. Y. Peng, J. F. Wang, and H.-L. Wang, "Field experiments on cyclic behaviors of axially loaded piles jacked in soft clay," Journal of Geotechnical and Geoenvironmental Engineering, vol. 147, no. 3, Article ID 04020176, 2021.

[12] K. Liu, Y. Yang, L. Wang, J. Xu, and X. Xie, "Experimental investigation of geosynthetic-reinforced pile-supported composite foundations under cyclic loading," Advances in Civil Engineering, vol. 2020, Article ID 8886131, 11 pages, 2020.

[13] S.-S. Lin and J.-C. Liao, "Permanent strains of piles in sand due to cyclic lateral loads," Journal of Geotechnical and Geoenvironmental Engineering, vol. 125, no. 9, pp. 798-802, 1999.

[14] F. Rosquoët, L. Thorel, J. Garnier, and Y. Canepa, "Lateral cyclic loading of sand-installed piles," Soils and Foundations, vol. 47 , no. 5, pp. 821-832, 2007.

[15] X. Zhang, M. S. Huang, and Z. P. Hu, "Model tests on cumulative deformation characteristics of a single pile subjected to lateral cyclic loading in sand," Rock and Soil Mechanics, vol. 40, no. 3, pp. 933-741, 2019.

[16] C. LeBlanc, G. T. Houlsby, and B. W. Byrne, "Response of stiff piles in sand to long-term cyclic lateral loading," Géotechnique, vol. 60, no. 2, pp. 79-90, 2010.

[17] M. Arshad and B. C. O’Kelly, "Model studies on monopile behavior under long-term repeated lateral loading," International Journal of Geomechanics, vol. 17, no. 1, Article ID 04016040, 2017.

[18] I. A. Richards, B. W. Byrne, and G. T. Houlsby, "Monopile rotation under complex cyclic lateral loading in sand," Géotechnique, vol. 70, no. 10, pp. 916-930, 2020.

[19] Z. Li, S. K. Haigh, and M. D. Bolton, "Centrifuge modelling of mono-pile under cyclic lateral loads," Physical Modelling in Geotechnics, vol. 2, pp. 965-970, 2010.

[20] Mr Alizadeh and M. T. Davisson, "Lateral load tests on pilesArkansas River project," Journal of the Soil Mechanics and Foundations Division, vol. 96, 1970.

[21] R. L. Little and J. L. Briaud, Full Scale Cyclic Lateral Load Tests on Six Single Piles in Sand, Texas A and M Univ College Station Dept of Civil Engineering, College Station, TX, USA, 1988.

[22] J. H. Long and G. Vanneste, "Effects of cyclic lateral loads on piles in sand," Journal of Geotechnical Engineering, vol. 120, no. 1, pp. 225-244, 1994.

[23] L. Verdure, J. Garnier, and D. Levacher, "Lateral cyclic loading of single piles in sand," International Journal of Physical Modelling in Geotechnics, vol. 3, no. 3, pp. 17-28, 2003.

[24] R. P. Luo, W. C. Li, and M. M. Yang, "Accumulated response of offshore large-diameter monopile under lateral cyclic loading," Rock and Soil Mechanics, vol. 37, no. S2, pp. 607-612, 2016.

[25] P. Peralta and M. Achmus, "An experimental investigation of piles in sand subjected to lateral cyclic loads," in Proceedings of the 7th International Conference on Physical Modeling in Geotechnics, Zurich, Switzerland, June 2010.

[26] Profession Standard of the People's Republic of China, Code For Pile Foundation Of Harbor Engineering JTS 167-4-2012, Profession Standard of the People's Republic of China, Beijing, China, 2012.
[27] Profession Standard of the People's Republic of China, Specification For Seismic Test of Buildings JGJ/T 101-2015, Profession Standard of the People's Republic of China, Beijing, China, 2015.

[28] W. L. Jin and Z. G. Song, "Numerical simulation of pile dynamic characteristics under lateral recycling load," Ocean Engineering, vol. 21, no. 1, pp. 13-18, 2003.

[29] E. Winkler, Die Lehre von der Elasticität und Festigkeit mit besonderer Rücksicht auf ihre Anwendung in der Technik, Dominicius, Prague, 1867.

[30] J. Qu, J. P. Sun, and X. Gao, "Model test study of single stiffened micropile under cyclic load," Rock and Soil Mechanics, vol. 32, no. S2, pp. 329-333, 2011.

[31] Profession Standard of the People's Republic of China, Specificating Of Testing Methods For Earthquake Resistant Building JGJ 101-96, Profession Standard of the People's Republic of China, Beijing, China, 1997. 